\title{
Protein Kinase C-Mediated Phosphorylation and $\alpha 2 \delta$-1 Interdependently Regulate NMDA Receptor Trafficking and Activity
}

\author{
Meng-Hua Zhou (周孟华), Shao-Rui Chen (陈少瑞), Li Wang (王力), Yuying Huang (黄玉莹), \\ Meichun Deng (邓梅春), ${ }^{\circledR}$ Jixiang Zhang (张吉祥), Jiyuan Zhang (张继远), Hong Chen (陈红), \\ Jiusheng Yan (问久胜), and ${ }^{\circledR}$ Hui-Lin Pan (潘惠麟) \\ Department of Anesthesiology and Perioperative Medicine, University of Texas MD Anderson Cancer Center, Houston, Texas 77030
}

$N$-methyl-D-aspartate receptors (NMDARs) are important for synaptic plasticity associated with many physiological functions and neurologic disorders. Protein kinase C (PKC) activation increases the phosphorylation and activity of NMDARs, and $\alpha 2 \delta$ 1 is a critical NMDAR-interacting protein and controls synaptic trafficking of NMDARs. In this study, we determined the relative roles of PKC and $\alpha 2 \delta$-1 in the control of NMDAR activity. We found that $\alpha 2 \delta$-1 coexpression significantly increased NMDAR activity in HEK293 cells transfected with GluN1/GluN2A or GluN1/GluN2B. PKC activation with phorbol 12-myristate 13-acetate (PMA) increased receptor activity only in cells coexpressing GluN1/GluN2A and $\alpha 2 \delta$-1. Remarkably, PKC inhibition with Gö6983 abolished $\alpha 2 \delta$-1-coexpression-induced potentiation of NMDAR activity in cells transfected with GluN1/ GluN2A or GluN1/GluN2B. Treatment with PMA increased the $\alpha 2 \delta$-1-GluN1 interaction and promoted $\alpha 2 \delta$-1 and GluN1 cell surface trafficking. PMA also significantly increased NMDAR activity of spinal dorsal horn neurons and the amount of $\alpha 2 \delta$ 1-bound GluN1 protein complexes in spinal cord synaptosomes in wild-type mice, but not in $\alpha 2 \delta$-1 knockout mice. Furthermore, inhibiting $\alpha 2 \delta$-1 with pregabalin or disrupting the $\alpha 2 \delta$-1-NMDAR interaction with the $\alpha 2 \delta$-1 C-terminus peptide abolished the potentiating effect of PMA on NMDAR activity. Additionally, using quantitative phosphoproteomics and mutagenesis analyses, we identified S929 on GluN2A and S1413 (S1415 in humans) on GluN2B as the phosphorylation sites responsible for NMDAR potentiation by PKC and $\alpha 2 \delta$-1. Together, our findings demonstrate the interdependence of $\alpha 2 \delta$-1 and PKC phosphorylation in regulating NMDAR trafficking and activity. The phosphorylation-dependent, dynamic $\alpha 2 \delta$-1NMDAR interaction constitutes an important molecular mechanism of synaptic plasticity.

Key words: gabapentin; gabapentinoid; neuropathic pain; NMDA receptor; phosphorylation; signal transduction; synaptic plasticity

Significance Statement

A major challenge in studies of protein phosphorylation is to define the functional significance of each phosphorylation event and determine how various signaling pathways are coordinated in response to neuronal activity to shape synaptic plasticity. PKC phosphorylates transporters, ion channels, and G-protein-coupled receptors in signal transduction. In this study, we showed that $\alpha 2 \delta-1$ is indispensable for PKC-activation-induced surface and synaptic trafficking of NMDARs, whereas the $\alpha 2 \delta$-1-NMDAR interaction is controlled by PKC-induced phosphorylation. Our findings reveal that $\alpha 2 \delta$-1 mainly functions as a phospho-binding protein in the control of NMDAR trafficking and activity. This information provides new mechanistic insight into the reciprocal roles of PKC-mediated phosphorylation and $\alpha 2 \delta-1$ in regulating NMDARs and in the therapeutic actions of gabapentinoids.

Received Apr. 9, 2021; revised May 25, 2021; accepted May 29, 2021.

Author contributions: H.-L.P. designed research; M.-H.Z., S.-R.C., L.W., Y.H., M.D., Jixiang Zhang, and H.C. performed research; M.-H.Z., S.-R.C., L.W., Y.H., M.D., Jixiang Zhang, Jiyuan Zhang, J.Y., and H.-L.P. analyzed data; M.-H.Z., S.-R.C., and H.-L.P. wrote the paper.

This study was supported by Grants GM120844, NS101880, and DA041711 from the National Institutes of Health and by the N. G. and Helen T. Hawkins Endowment. Mass spectrometry raw data were collected at the University of Texas Southwestern Medical Center.

The authors declare no competing financial interests.

Correspondence should be addressed to Hui-Lin Pan at huilinpan@mdanderson.org.

https://doi.org/10.1523/JNEUROSCI.0757-21.2021

Copyright $\odot 2021$ the authors

\section{Introduction}

The glutamate $N$-methyl-D-aspartate receptors (NMDARs) are expressed at most excitatory synapses and play a critical role in neural development and learning and memory (Collingridge and Bliss, 1995; Butler et al., 1998). Dysregulated NMDARs are involved in many neurologic disorders, including Alzheimer's disease and neuropathic pain (Chohan and Iqbal, 2006; Zhou et al., 2011). Phosphorylation of the C-terminal domains of NMDARs is a fundamental mechanism that regulates NMDAR activity and 
synaptic plasticity (Chen and Roche, 2007; Rebola et al., 2010; Warnet et al., 2020). Protein kinase C (PKC) is a family of serine/ threonine kinases that function as key signal transducers in potentiated NMDAR activity in chronic pain, opioid tolerance, neurogenic hypertension, and stroke (Mao et al., 1994; Lan et al., 2001; Bright and Mochly-Rosen, 2005; Zhao et al., 2012; Li et al., 2014). However, direct phosphorylation of NMDAR subunits does not appear to mediate PKC-activation-induced NMDAR activity reconstituted in cell lines (Zheng et al., 1999). Although several PKC-targeted phosphorylation sites in NMDAR subunits have been reported previously (Gardoni et al., 2001; Liao et al., 2001; Krupp et al., 2002), their functional significance in regulating NMDAR activity is largely unknown.

$\alpha 2 \delta$-1, originally identified as an auxiliary subunit of voltagedependent calcium channels (Liu et al., 1996), is the target of widely prescribed gabapentinoids, including gabapentin and pregabalin (Bian et al., 2006; Fuller-Bicer et al., 2009), for treating neuropathic pain and epilepsy. Recent studies revealed that $\alpha 2 \delta$ 1 is a key NMDAR-interacting protein that controls the trafficking and activity of NMDARs independent of calcium channels (Chen et al., 2018; Luo et al., 2018; Zhou et al., 2018). $\alpha 2 \delta$-1bound NMDARs are critically involved in learning and memory, neuropathic pain, stroke, and hypertension (Chen et al., 2018, 2019; Luo et al., 2018; Ma et al., 2018; Zhou et al., 2018). Phosphorylation can modulate the nature and strength of protein-protein interactions (Nishi et al., 2011). Inhibition of calcineurin, a $\mathrm{Ca}^{2+} /$ calmodulin-activated serine/threonine protein phosphatase, potentiates NMDAR activity and increases the $\alpha 2 \delta$-1-NMDAR interaction in the spinal cord (Chen et al., 2014a; Huang et al., 2020), suggesting a potential role of protein phosphorylation in regulating $\alpha 2 \delta$-1-bound NMDARs. However, most studies on phosphorylation-mediated NMDAR regulation used neural tissues, primary cultured neurons, and neuronal cell lines (Chen and Huang, 1992; George et al., 2011; Chen et al., 2014b; Lussier et al., 2015), which express endogenously different levels of $\alpha 2 \delta-1$ and other NMDAR-interacting proteins. It is thus difficult to define the functional significance of PKC-mediated phosphorylation and $\alpha 2 \delta-1$ in the regulation of NMDARs.

In the current study, we mainly used a recombinant expression system to determine the respective roles of $\alpha 2 \delta-1$ and PKCmediated phosphorylation in the control of NMDAR activity. We demonstrated that $\alpha 2 \delta-1$ is required for PKC-activation-induced increases in NMDAR activity and surface trafficking, which is independent of other NMDAR-interacting proteins. Remarkably, the physical interaction between $\alpha 2 \delta-1$ and NMDARs critically depends on PKC activity. We also identified the key phosphorylation sites at the $\mathrm{C}$ terminus of GluN2A and GluN2B involved in the potentiation of NMDAR activity by $\alpha 2 \delta-1$ and PKC activity. This new information advances our understanding of the molecular mechanisms of NMDAR regulation and synaptic plasticity.

\section{Materials and Methods}

Cell culture and transfection. Human embryonic kidney (HEK) 293 cells were cultured in Dulbecco's Modified Eagle Medium (Invitrogen) supplemented with $10 \%$ fetal bovine serum (Sigma-Aldrich) at $37^{\circ} \mathrm{C}$ in $5 \% \mathrm{CO}_{2}$ incubator. For cell transfection, $1.2 \times 104$ cells were plated on ploy-D-lysine-coated coverslips. GluN1/GluN2A or GluN1/GluN2B were transfected either alone or with $\alpha 2 \delta-1$. Coexpression of GFP was used to identify transfected cells for recording. The transfection ratio of
GluN1, GluN2A or GluN2B, and $\alpha 2 \delta-1$ was $1: 1: 1$ using PolyJet DNA In Vitro Transfection Reagent (SigaGen Laboratories). We replaced the culture medium with glutamine-free medium containing $100 \mu \mathrm{M}$ DL-AP5 (Abcam) after $4 \mathrm{~h}$ of transfections. Electrophysiological recordings were performed $24-48 \mathrm{~h}$ after transfection. The rat GluN1 and GluN2A cDNAs were provided by Vasanthi Jayaraman (University of Texas Health Sciences Center in Houston). To facilitate biochemical studies, the coding region of GluN1 was transferred to pCDNA6 and tagged with V5 and Flag epitopes on the protein's $\mathrm{C}$ terminus (Zhang et al., 2018). We obtained rat $\alpha 2 \delta-1 \mathrm{cDNA}$ from Diane Lipscombe (Brown University) and rat GluN2B cDNA from Stefano Vicini (Georgetown University).

Electrophysiological recording in HEK293 cells. Whole-cell patchclamp recordings of NMDAR currents reconstituted in HEK293 cells were performed using an EPC 10 amplifier (HEKA), as described previously (Chen et al., 2018). The extracellular recording solution consisted of the following (in mM): $150 \mathrm{NaCl}, 2.5 \mathrm{KCl}, 1 \mathrm{CaCl}_{2}, 10 \mathrm{HEPES}, 10$ glucose, and 0.01 glycine ( $\mathrm{pH} 7.3$; osmolarity, $320 \mathrm{mOsm}$ ). Electrodes (resistance, 4-6 M 2 ) were filled with pipette solution consisting of the following (in mM): $135 \mathrm{CsF}, 1 \mathrm{CaCl}_{2}, 11$ EGTA, $10 \mathrm{HEPES}$, and $2 \mathrm{Mg}$ ATP (pH 7.3; osmolarity, $300 \mathrm{mOsm}$ ). The cell membrane capacitance and series resistance were electronically compensated. Signals were recorded using the Pulse program (HEKA), filtered at $1 \mathrm{kHz}$, and digitized at $10 \mathrm{kHz}$. To elicit NMDAR currents, NMDA (300 $\mu \mathrm{M}$ for $5 \mathrm{~ms}$; Sigma-Aldrich) was applied using the VC38 perfusion system (ALA Scientific Instruments).

Phorbol 12-myristate 13-acetate (PMA), Gö6983, and pregabalin were purchased from Tocris Bioscience. The $\alpha 2 \delta-1 \mathrm{C}$ terminus mimicking peptide (VSGLNPSLWSIFGLQFILLWLVSGSRHYLW) fused with the cellpenetrating peptide Tat (YGRKKRRQRRR) and a scrambled control peptide (FGLGWQPWSLSFYLVWSGLILSVLHLIRSN) fused with Tat were synthesized by Synpeptide.

Site-directed mutagenesis. Point mutation was achieved by replacing serine with alanine at sites $\mathrm{S} 917$ and S929 on rat GluN2A or at sites S940, S1159, S1303, and S1413 on rat GluN2B. Primers were designed by In-Fusion Cloning Primer Design Tool on the Takara Bio website. Point mutations were achieved using In-Fusion HD Cloning Kit (Takara Bio) according to the manufacturer's instructions.

Quantitative PCR. RNA was extracted from HEK293 cells using TRIsure (catalog \#BIO-38 032, Bioline). After treatment with RNaseFree DNase (catalog \#79 254, Qiagen), 500 ng RNA was used for reverse transcription with the RevertAid RT Reverse Transcription Kit (catalog \#K1619, Thermo Fisher Scientific). Two $\mu \mathrm{l}$ of $5 \times$ diluted cDNA was added to a 20- $\mu$ l Sybr Green Real-time PCR system (catalog \#A25780, Thermo Fisher Scientific). Real-time PCR was performed using the QuantStudio 7 Flex Real-Time PCR System (Applied Biosystems). The thermal cycling conditions were as follows: 1 cycle at $95^{\circ} \mathrm{C}$ for $10 \mathrm{~min}$ and 40 cycles at $95^{\circ} \mathrm{C}$ for $15 \mathrm{~s}$ and at $60^{\circ} \mathrm{C}$ for $45 \mathrm{~s}$. Primers used were as follows: Prkca forward, GCT TCC AGT GCC AAG TTT GC; Prkca reverse, GCA CCC GGA CAA GAA AAA GTA A; Prkcb forward, CTT CTT CAA GCA GCC CAC CTT CT; Prkcb reverse, TAG TTA CCC ACA GAG TCA CCC GC; Prkcq forward, GCA AAA ACG TGG ACC TCA TCT; Prkcq reverse, CAA AGA AGC CTT CCG TCT CAA A; Prkch forward, TTT TGC GCT AAC GTC ACC GA; Prkch reverse, TGA AAC TCC CGG TAA GGG TTA TT; Prkce forward, CAA CGG ACG CAA GAT CGA G; Prkce reverse, CTG GCT CCA GAT CAA TCC AGT; Prkcd forward, AAC GCT GCC ATC CAC AAG AAA; Prkcd reverse, TTT AAT CCC TGC TTC ACC AGT C; Prkcg forward, GGA GAG GCC AGG GGA GGA AAT AAA; Prkcg reverse, GAG TGG GGA GGA AGA GCC AAA; Gapdh forward, GGA GCG AGA TCC CTC CAA AAT; Gapdh reverse, GGC TGT TGT CAT ACT TCT CAT GG. Data were analyzed using the comparative Ct method.

Generation of $\alpha 2 \delta-1 \mathrm{KO}$ mice. All experimental procedures were approved by the Institutional Animal Care and Use Committee of the University of Texas MD Anderson Cancer Center and conformed to the National Institutes of Health guidelines on the ethical use of animals. Two breeding pairs of $\alpha 2 \delta 1^{+/-}$mice (C57BL/6 genetic background) were purchased from the Medical Research Council (stock \#6900). Generation of $\alpha 2 \delta-1$ knock-out (KO, $\left.\alpha 2 \delta-1^{-/-}\right)$mice has been 
reported previously (Fuller-Bicer et al., 2009). $\alpha 2 \delta-1^{-/-}$and $\alpha 2 \delta-1^{+/+}$ wild-type (WT) littermates were generated by breeding the $\alpha 2 \delta-1^{+/-}$ heterozygous mice. Animals were earmarked at the time of weaning ( 3 weeks after birth), and tail biopsies were used for PCR genotyping. We used both male and female adult mice for electrophysiological experiments. Because we observed no differences in electrophysiological data between male and female mice, these data were pooled.

Electrophysiological recording in spinal cord slices. Mice were anesthetized with $2-3 \%$ isoflurane, and the lumbar spinal cord at the L4-L6 level was quickly removed via laminectomy. The spinal cords were placed immediately in ice-cold artificial cerebrospinal fluid containing the following (in mM) 234 sucrose, $3.6 \mathrm{KCl}, 26 \mathrm{NaHCO}_{3}, 1.2 \mathrm{NaH}_{2} \mathrm{PO}_{4}$, $2.5 \mathrm{CaCl}_{2}, 1.2 \mathrm{MgCl}_{2}$, and 25 glucose, presaturated with $95 \% \mathrm{O}_{2}$ and $5 \%$ $\mathrm{CO}_{2}$. The spinal cord tissue was then glued onto the stage of a vibratome, and transverse slices of $400 \mu \mathrm{m}$ were cut and incubated in Krebs solution containing the following (in $\mathrm{mm}$ ): $117 \mathrm{NaCl}, 3.6 \mathrm{KCl}, 25 \mathrm{NaHCO}_{3}, 1.2$ $\mathrm{NaH}_{2} \mathrm{PO}_{4}, 2.5 \mathrm{CaCl}_{2}, 1.2 \mathrm{MgCl}_{2}$, and 11 glucose, oxygenated with $95 \%$ $\mathrm{O}_{2}$ and $5 \% \mathrm{CO}_{2}$ at $34^{\circ} \mathrm{C}$ for at least $1 \mathrm{~h}$ before recording.

The spinal cord slices were placed in a recording chamber and continuously perfused with oxygenated Krebs solution at $3 \mathrm{ml} / \mathrm{min}$ at $34^{\circ} \mathrm{C}$. The lamina II outer neurons were identified for recording under a microscope with a combination of infrared illumination and differential interference contrast (Chen et al., 2014a, 2018). The NMDAR currents were elicited and recorded by puff application of $100 \mu \mathrm{M}$ NMDA directly onto the neuron at a $30^{\circ}$ angle using a positive pressure system (Toohey). The distance was $\sim 150 \mu \mathrm{m}$ between the tip of the puff pipette and the recorded neuron (Chen et al., 2014a,b). The internal solution used for recording electrodes contained the following (in $\mathrm{mM}$ ): 110 $\mathrm{Cs}_{2} \mathrm{SO}_{4}, 0.5 \mathrm{CaCl}_{2}, 2.4 \mathrm{CaCl}_{2}$, 5 EGTA, 10 HEPES, $2 \mathrm{Mg}$-ATP, 0.3 GTPTris salt, and 10 QX314 (pH 7.3; 280-290 mOsm). All signals were filtered at $1-2 \mathrm{kHz}$ and digitized at $10 \mathrm{kHz}$ using an amplifier (MultiClamp 700B, Molecular Devices).

Synaptosome preparation. Synaptosomes were isolated from the dorsal spinal cord, as described previously (Chen et al., 2018, 2019). Synaptic proteins were extracted and enriched using Syn-PER reagent (Thermo Fisher Scientific) containing $1 \times$ Halt Protease and Phosphatase Inhibitor Cocktail (Thermo Fisher Scientific). The homogenate was centrifuged at $1200 \times g$ for $10 \mathrm{~min}$ at $4^{\circ} \mathrm{C}$ to remove the nuclei and large debris. The supernatant was then centrifuged at $15,000 \times g$ for $20 \mathrm{~min}$ to obtain the crude synaptosomes. The synaptosomal pellet was incubated in RIPA lysis buffer with a protease and phosphatase inhibitor cocktail for $1 \mathrm{~h}$ on ice and then centrifuged at $16,000 \times g$ for $15 \mathrm{~min}$ at $4^{\circ} \mathrm{C}$ to obtain the synaptosomal proteins for immunoblotting analysis. The synaptosomal proteins were probed with rabbit anti-GluN1 antibody (1:1000; catalog \#G8913, Sigma-Aldrich), a mouse anti- $\alpha 2 \delta$-1 antibody (1:1000; catalog \#sc271697, Santa Cruz Biotechnology), or a mouse anti-PSD-95 antibody (1:1000; catalog \#75-348, NeuroMab). Immunoblotting data were quantified using LI-COR Image Studio software (LI-COR Biosciences).

Coimmunoprecipitation. HEK293 cells were cotransfected with Flag/ V5-tagged GluN1/GluN2A and $\alpha 2 \delta-1$. After $48 \mathrm{~h}$ of transfection, cells were subjected to different treatments for $30 \mathrm{~min}$. For coimmunoprecipitation experiments, a rabbit anti-GluN1 antibody (catalog \#G8913, Sigma-Aldrich) was preincubated with protein $\mathrm{G}$ agarose beads (EMD Millipore) at $22^{\circ} \mathrm{C}$ for $1 \mathrm{~h}$. Antibody-linked beads were added to the whole-cell lysis at $4^{\circ} \mathrm{C}$ overnight. After the pulldown, the protein complex was eluted using $4 \%$ SDS for immunoblotting analysis. The precipitated proteins were probed with mouse anti-V5 (1:1000; catalog $\# 2148086$, Invitrogen) or mouse anti- $\alpha 2 \delta-1$ antibodies (1:1000; catalog \#sc-271697, Santa Cruz Biotechnology).

Cell surface biotinylation assay. The isolation of cell surface biotinylation and surface protein was conducted using the Cell surface Protein Isolation Kit (Pierce Biotechnology), as we described previously (Chen et al., 2018). The surface protein samples were probed with a rabbit antiGluN1 antibody (1:1000; Sigma-Aldrich), a mouse anti- $\alpha 2 \delta$ - 1 antibody (1:1000; Santa Cruz Biotechnology), and a mouse anti- $\mathrm{Na}^{+}-\mathrm{K}^{+}$ATPase antibody (1:1000; catalog \#ab7671, Abcam). Protein amounts were quantified using immunoblotting. $\mathrm{Na}^{+}-\mathrm{K}^{+}$ATPase, a plasma membrane protein, was used as a loading control. Amounts of GluN1 and $\alpha 2 \delta-1$ proteins were normalized to the protein band of $\mathrm{Na}^{+}-\mathrm{K}^{+}$ATPase on the same blot.

In situ proximity ligation assay. HEK293 cells were cotransfected with GluN1/GluN2A and $\alpha 2 \delta$-1-GFP. Forty-eight h after transfection, the Duolink proximity ligation assay (PLA) signal of GluN1/GluN2A protein complexes was detected using mouse anti- $\alpha 2 \delta-1$ and rabbit anti-GluN1 antibodies. The PLA was performed using the Duolink In Situ kit (Sigma-Aldrich) according to the manufacturer's instruction and as reported (Zhang et al., 2018). The cultured HEK293 cells were treated with $1 \mu \mathrm{M}$ Gö6983, $1 \mu \mathrm{M}$ PMA, or vehicle for $30 \mathrm{~min}$ and then fixed with $4 \%$ paraformaldehyde for $10 \mathrm{~min}$ at $25^{\circ} \mathrm{C}$. Fixed cells were blocked using the blocking solution in a preheated humidity chamber for $30 \mathrm{~min}$ at $37^{\circ}$ C. After removing the blocking solution, we added rabbit anti-GluN1 (1:1000; catalog \#G8913, Sigma-Aldrich) and mouse anti- $\alpha 2 \delta-1$ (1:1000; catalog \#sc-271697, Santa Cruz Biotechnology) antibodies diluted in the antibody diluent. After incubating the sample with primary antibodies in a humidity chamber overnight at $4^{\circ} \mathrm{C}$, we washed the slides twice in $1 \times$ Wash Buffer A for $5 \mathrm{~min}$. We next diluted the PLA probes (rabbit and mouse secondary antibodies, each with a unique short DNA strand attached to it) in antibody diluent and incubated the slides in a humidity chamber for $1 \mathrm{~h}$ at $37^{\circ} \mathrm{C}$. We washed the slides twice in $1 \times$ Wash Buffer A for 5 min each time under gentle agitation and then added diluted ligation-ligase solution to the samples and incubated them in the humidity chamber for $30 \mathrm{~min}$ at $37^{\circ} \mathrm{C}$. After the prediluted amplificationpolymerase solution was added, the slides were washed, dried, mounted, and imaged using a fluorescence microscope. The $\alpha 2 \delta-1-\mathrm{GluN1}$ punctate signals in individual cells were quantified using ImageJ software and the Cell Counter Plugin.

Quantitative proteomic analyses of NMDAR phosphorylation. The stable isotope labeling by amino acids in cell culture (SILAC) was performed using SILAC Protein Quantitation Kits (Thermo Scientific) according to the manufacturer's instruction. Briefly, HEK293 cells were cultured in SILAC-compatible Dulbecco's Modified Eagle Medium supplemented with $10 \%$ dialyzed fetal bovine serum and $50 \mathrm{mg}{ }^{13} \mathrm{C}$ (heavy)or ${ }^{12} \mathrm{C}$ (light)-labeled lysine and arginine for $10 \mathrm{~d}$. Equal amounts of HEK293 cells prelabeled with either heavy or light isotopes were cotransfected with $\alpha 2 \delta-1$ and Flag/V5-tagged GluN1/GluN2A or Flag/V5tagged GluN1/GluN2B. After $48 \mathrm{~h}$ of culture, the light group was treated with $1 \mu \mathrm{M}$ Gö6983, and the heavy group was treated with $1 \mu \mathrm{M}$ PMA for $30 \mathrm{~min}$. For SILAC quantification by mass spectrometry (MS), the proteins immunoprecipitated with an anti-Flag antibody from heavy- and light-labeled cells were merged, separated by SDS-PAGE, and visualized with Coomassie G-250 (Thermo Fischer Scientific). Protein bands were excised, washed thoroughly with $50 \%$ acetonitrile in $25 \mathrm{~mm}$ ammonium bicarbonate, and then subjected to in-gel reduction with dithiothreitol, alkylation with iodoacetamide, and digestion with trypsin as previously reported (Yan et al., 2008). Digested peptide mixtures were extracted and dried in a speed vacuum concentrator. Samples were reconstituted into $2 \%$ acetonitrile and $0.1 \%$ trifluoroethanol and analyzed with an Orbitrap Fusion Lumos mass spectrometer coupled to an Ultimate 3000 RSLC Nano liquid chromatography system (Thermo Fisher Scientific). Samples were injected onto a $75 \mathrm{~cm}$ EasySpray column with $75-\mu \mathrm{m}$ inner diameter (Thermo Fisher Scientific) and eluted with a gradient of $0-28 \%$ buffer B in buffer A over 90 min. Buffer A contained 2\% (v/v) acetonitrile and $0.1 \%$ formic acid in water, and buffer B contained $80 \%(\mathrm{v} / \mathrm{v})$ acetonitrile, $10 \%(\mathrm{v} / \mathrm{v})$ trifluoroethanol, and $0.1 \%$ formic acid in water. The mass spectrometer operated in positive ion mode with a source voltage of $1.5-2.4 \mathrm{kV}$ and an ion transfer tube temperature of $275^{\circ} \mathrm{C}$. MS scans were acquired in the Orbitrap, and up to 10 tandem mass spectrometry (MS/MS) spectra were obtained in the ion trap (0.6-Da mass resolution) for each full spectrum acquired using higher energy collisional dissociation for ions with charges 2-7. Dynamic exclusion was set for $25 \mathrm{~s}$ after an ion was selected for fragmentation. The spectra labeling, database search, and quantification were conducted using Mascot Distiller (version 2.6 or 2.7) and Mascot (version 2.4 or 2.7;). MS/MS spectra were searched against the human UniProt proteomes database (release 2020_09, 75,069 protein entries) supplemented with rat NMDAR and $\alpha 2 \delta-1$ protein sequences. Database searches were performed with a peptide mass tolerance of $20 \mathrm{ppm}$ and an MS/MS 


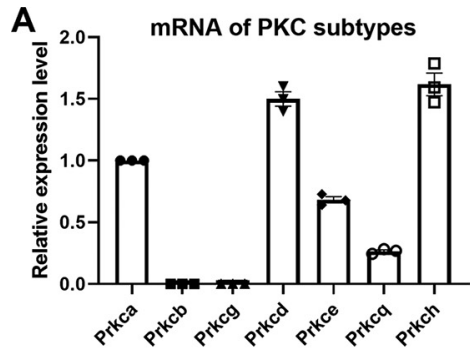

B
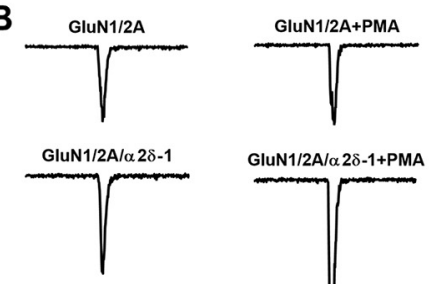

C

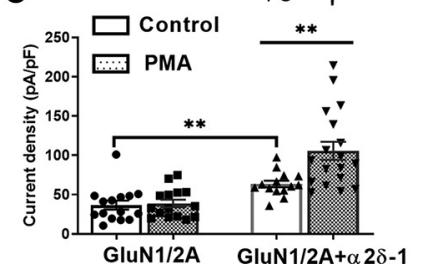

D

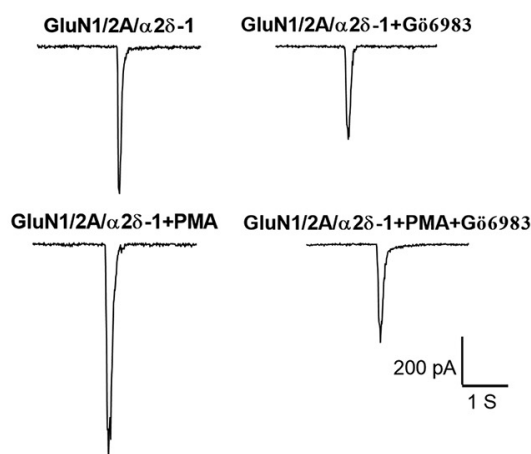

E
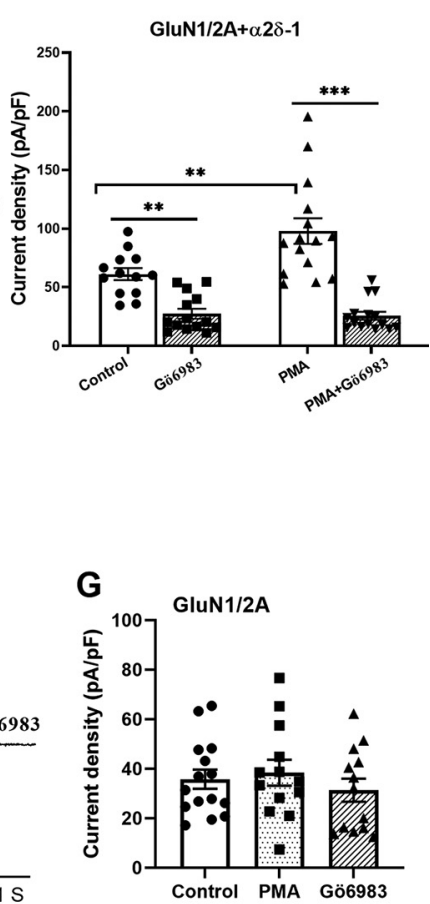

Figure 1. $\quad \alpha 2 \delta-1$ is required for PKC-activation-induced GluN2A-containing NMDAR currents. A, Quantitative PCR results show the relative mRNA levels of PKC isoforms in HEK293 cells. Gapdh was used as a control ( $n=3$ biological replicates). $\boldsymbol{B}, \boldsymbol{C}$, Original current traces $(\boldsymbol{B})$ and mean data (C) show the effect of $\alpha 2 \delta-1$ coexpression and PMA treatment (1 $\mu \mathrm{m}$ for 30 min) on the whole-cell current elicited by NMDA (300 $\mu \mathrm{m}$ for $5 \mathrm{~ms}$ ) in HEK293 cells expressing GluN1/GluN2A ( $n=15$ cells in the control group, $n=15$ cells in the PMA group) or GluN1/GluN2A/ $\alpha 2 \delta-1$ ( $n=17$ cells in the control group, $n=18$ cells in the PMA group). $\boldsymbol{D}, \boldsymbol{E}$, Original recording traces $(\boldsymbol{D})$ and mean data $(\boldsymbol{E})$ show that treatment with Gö6983 (1 $\mu \mathrm{m}$ for 30 min) reduced $\alpha 2 \delta$-1 coexpression-induced increase in GluN1/GluN2A currents ( $n=13$ cells in the control group, $n=14$ cells in the Gö6983 group) and also abolished the potentiating effect of PMA on receptor currents elicited by NMDA application ( $n=15$ cells in the PMA group, $n=15$ cells in the PMA + Gö6983 group). $\boldsymbol{F}$, G, Original recording traces $(\boldsymbol{F})$ and mean data $(\boldsymbol{G})$ show that neither PMA nor Gö6983 changed GluN1/GluN2A activity in the absence of $\alpha 2 \delta-1$ ( $n=15$ cells in the control group, $n=13$ cells in the PMA group, $n=13$ cells in the Gö698 group). Data are expressed as means \pm SEM. ${ }^{* *} p<0.01$, ${ }^{* * *} p<0.001$ versus the corresponding control (one-way ANOVA followed by Tukey's post hoc test).

tolerance of 0.5 or $0.6 \mathrm{Da}$, allowing two missed cleavage sites and variable modifications of SILAC $(\mathrm{K}+6, \mathrm{R}+6$, ArgPro), oxidation $(\mathrm{M})$, N-terminal pyroglutamate (pyro-Glu), and phosphorylation (Ser, Thr, and Tyr). MS/MS spectra exhibiting possible phosphorylation were manually checked. Annotated MS/MS spectra were generated by labeling only matches used for scoring with Mascot (version 2.7).

Experimental design and statistical analysis. Data are presented as means \pm SEM, with $n$ indicating the number of cells used for the electrophysiological recording or the number of independent repeats for biochemical experiments. No statistical methods were used to predetermine sample sizes for the studies, but our sample sizes were similar to those generally employed in the field (Chen et al., 2014a, 2018; Huang et al., 2020). Recording data in HEK293 cells were analyzed using Pulse software (HEKA), and the current density was calculated by normalizing the current to capacitance to account for differences in cell sizes. The amplitude of puff NMDA currents of spinal dorsal horn neurons was analyzed and averaged using the Clampfit 10.0 software program (Molecular Devices). We used Student's $t$ test to compare two groups and one-way ANOVA to compare more than two groups. Statistical analyses were conducted using Prism 8 software (GraphPad). Differences were considered statistically significant if the $p$ value was $<0.05$.

\section{Results}

$\alpha 2 \delta$-1 is required for increases in PKC-activation-induced GluN2A-containing NMDAR activity

NMDARs are heterotetramers composed of two obligatory GluN1 subunits and two GluN2 or GluN3 subunits. GluN2A and GluN2B are highly expressed in the spinal dorsal horn and contribute to neuropathic pain and opioid tolerance (Zhao et al., 2012; Chen et al., 2014a,b). Because $\alpha 2 \delta-1$ and many other NMDAR-interacting proteins are widely expressed in neural tissues (Husi et al., 2000; Cole et al., 2005), we used a heterologous expression system to specifically determine whether PKC-activation-augmented NMDAR activity depends on $\alpha 2 \delta$-1. Constitutive PKC activity is present in HEK293 cells (Qian et al., 1997). Our quantitative PCR analysis showed that HEK293 cells endogenously expressed several isoforms of PKC, including Prkca (PKC $\alpha)$, Prkcd (PKC $\delta)$, Prkce (PKC $\varepsilon$ ), Prkch (PKC $\eta$ ), and Prkcq (PKC $\theta$; Fig. 1A). The mRNA levels of Prkca, Prkcd, and Prkch were relatively high, whereas the mRNA levels of Prkcb (PKC $\beta$ ) and Prkcg (PKC $\gamma$ ) were very low in HEK293 cells.

We first determined whether $\alpha 2 \delta-1$ is required for PKCactivation-induced GluN2A-containing NMDAR activity in HEK293 cells expressing NMDAR subunits with or without $\alpha 2 \delta$-1. In HEK293 cells transfected with GluN1/GluN2A alone, treatment with $1 \mu \mathrm{M}$ PMA, a potent PKC activator, for $30 \mathrm{~min}$ had no significant effect on the whole-cell receptor current $(n=$ 15 cells per group; Fig. $1 B, C)$. In contrast, in HEK293 cells cotransfected with GluN1/GluN2A and $\alpha 2 \delta-1$, treatment with 1 $\mu \mathrm{M}$ PMA caused a $54 \%$ increase in the current density $(n=17$ cells in the control group, $n=18$ cells in the PMA group; $F_{(3,61)}=21.23, p=0.0024$; Fig. $\left.1 B, C\right)$. The basal receptor current was significantly higher in cells cotransfected with GluN1/ GluN2A and $\alpha 2 \delta-1$ than in cells transfected with GluN1/ GluN2A alone $\left(F_{(3,61)}=21.23, p=0.007\right)$. These results indicate 
A
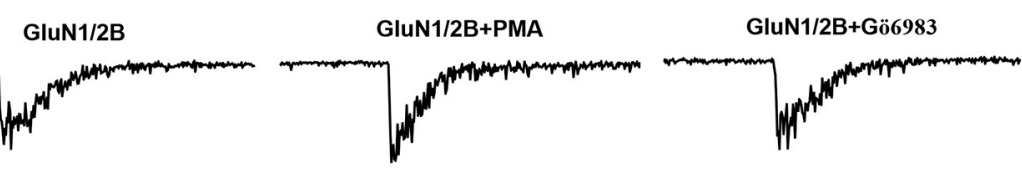

GluN1/2B/ $\alpha 2 \delta-1$
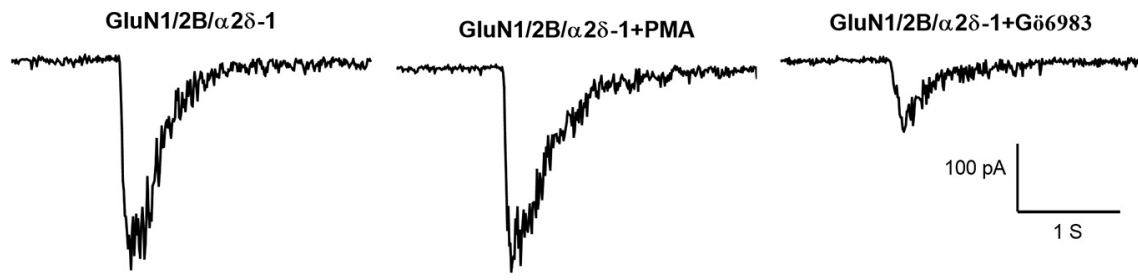

B

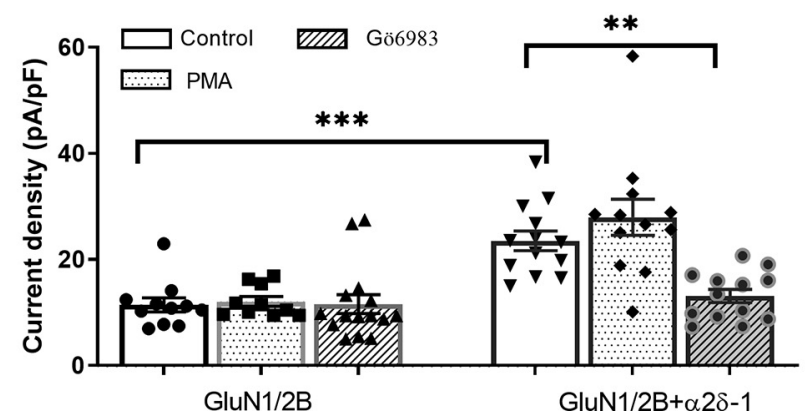

Figure 2. PKC inhibition blocks $\alpha 2 \delta-1$ coexpression-induced increases in GluN2B-containing NMDAR currents. $\boldsymbol{A}, \boldsymbol{B}$, Original current traces $(\boldsymbol{A})$ and mean data $(\boldsymbol{B})$ show the effect of $1 \mu \mathrm{M}$ PMA or $1 \mu \mathrm{m}$ Gö6983 on NMDAR currents elicited by NMDA (300 $\mu \mathrm{m}$ for $5 \mathrm{~ms}$ ) in HEK293 cells expressing GluN1/GluN2B alone ( $n=11$ cells in the control group, $n=10$ cells in the PMA group, $n=15$ cells in the Gö6983 group) or GluN1/GluN2B plus $\alpha 2 \delta-1$ ( $n=13$ cells in the control group, $n=12$ cells in the PMA group, $n=13$ in the Gö6983 group). Data are expressed as means \pm SEM, ${ }^{* *} p<0.01$, ${ }^{* *} p<0.001$ versus the control (one-way ANOVA followed by Tukey's post hoc test).

that $\alpha 2 \delta$-1 is essential for the potentiation of GluN2A-containing NMDAR activity by PKC activation.

PKC activity is essential for the potentiation of GluN2Acontaining NMDAR activity by $\boldsymbol{\alpha} \mathbf{2} \boldsymbol{\delta}$-1

We next determined whether intrinsic PKC activity is important for $\alpha 2 \delta$-1-coexpression-induced potentiation of GluN1/GluN2A activity. Treatment with $1 \mu \mathrm{M}$ Gö6983, a broad-spectrum PKC inhibitor (Gschwendt et al., 1996; Young et al., 2005), for 30 min significantly reduced the basal receptor current in HEK293 cells cotransfected with GluN1/GluN2A and $\alpha 2 \delta-1$ ( $n=13$ cells in the control group, $n=14$ cells in the Gö6983 group; $F_{(3,53)}=26.11, p=0.0064$; Fig. $1 D$, E). However, in HEK293 cells transfected with GluN1/GluN2A alone, treatment with Gö6983 had no significant effect on the current density ( $n=15$ cells in the control group, $n=13$ cells in the Gö6983 group; Fig. $1 F, G)$. In the presence of $1 \mu \mathrm{M}$ Gö6983, treatment with 1 $\mu \mathrm{M}$ PMA failed to increase the receptor current in HEK293 cells cotransfected with GluN1/GluN2A and $\alpha 2 \delta-1$ ( $n=15$ cells; Fig. $1 D$, $E$ ). These results indicate that intrinsic PKC activity is required for the potentiation of GluN2A-containing NMDAR activity by $\alpha 2 \delta-1$.

Tonic PKC activity is sufficient for $\alpha 2 \delta$-1-induced increases in GluN2B-containing NMDAR activity

We then determined whether $\alpha 2 \delta-1$ coexpression is also essential for the regulation of GluN2B-containing NMDAR activity by PKC. In HEK293 cells transfected with GluN1/GluN2B alone, treatment with PMA had no significant effect on the current density ( $n=11$ cells in the control group, $n=10$ cells in the PMA group; Fig. 2). Interestingly, in HEK293 cells coexpressing $\alpha 2 \delta$-1 with GluN1/GluN2B, treatment with PMA also failed to significantly increase the receptor current $(n=13$ cells in the control group, $n=12$ cells in the PMA group; Fig. 2).

In HEK293 cells transfected with GluN1/ GluN2B alone, treatment with Gö6983 had no significant effect on the receptor current ( $n=15$ cells; Fig. 2 ). However, in HEK293 cells coexpressing $\alpha 2 \delta-1$ with GluN1/ GluN2B, Gö6983 caused a 44\% reduction in the receptor current, at a level similar to that of HEK293 cells transfected with GluN1/ GluN2B alone ( $n=13$ cells per group; $F_{(5,68)}$ $=13.37, p=0.0037$; Fig. 2 ). The basal current was significantly higher in cells cotransfected with GluN1/GluN2B and $\alpha 2 \delta-1$ than in cells transfected with GluN1/GluN2B alone $\left(F_{(5,68)}=13.37, p=0.0009\right)$. These data suggest that constitutive PKC activity is sufficient for the potentiation of GluN2Bcontaining NMDAR activity by $\alpha 2 \delta-1$.

Bec.ause PMA did not further increase the activity of GluN2B-containing NMDARs potentiated by $\alpha 2 \delta-1$, we focused on the role of $\alpha 2 \delta-1$ in PKC-stimulationinduced potentiation of GluN2A-containing NMDARs in the following experiments.

$\boldsymbol{\alpha} \boldsymbol{2} \delta$-1 is essential for PKC-activationinduced increases in cell surface expression of NMDARs

$\alpha 2 \delta-1$ promotes NMDAR surface and synaptic trafficking without affecting NMDAR channel kinetics (Chen et al., 2018). GluN1 is an obligatory subunit of NMDARs (Traynelis et al., 2010). We thus used biotinylation to isolate cell surface proteins and determined whether PKC activation increases GluN1 surface trafficking in the presence of $\alpha 2 \delta-1$. Immunoblotting showed that treatment with PMA significantly increased the surface protein levels of both GluN1 and $\alpha 2 \delta-1$ in HEK293 cells cotransfected with GluN1/GluN2A and $\alpha 2 \delta-1 \quad(n=8$ independent experiments; Fig. $3 A, C)$. However, PMA had no significant effect on the GluN1 level in HEK293 cells transfected with GluN1/GluN2A alone ( $n=8$ independent experiments; Fig. $3 A, B)$. These results suggest that PKC-activation-induced surface trafficking of NMDARs critically depends on $\alpha 2 \delta-1$.

$\alpha 2 \delta$-1 is required for $\mathrm{PKC}$-activation-induced potentiation in the activity and synaptic trafficking of native NMDARs in the spinal cord

PKC activity regulates synaptic NMDARs in the spinal cord and brain (Ben-Ari et al., 1992; Xie et al., 2017a,b). $\alpha 2 \delta-1$ is expressed in the dorsal root ganglion and superficial dorsal horn of the spinal cord (Cole et al., 2005), and overexpression of $\alpha 2 \delta$ 1 potentiates NMDAR activity in the spinal dorsal horn (Chen et al., 2018). To determine the role of $\alpha 2 \delta-1$ in PKC-activationinduced NMDAR activity in the spinal cord, we recorded NMDAR currents elicited by puff application of $100 \mu \mathrm{M}$ NMDA directly onto spinal lamina II neurons (Chen et al., 2014a; Huang et al., 2020). Dorsal spinal cord slices from WT and $\alpha 2 \delta-1 \mathrm{KO}$ mice were treated with $1 \mu \mathrm{M}$ PMA or vehicle for $30 \mathrm{~min}$. In WT 
mice, PMA caused a large increase in the amplitude of puff NMDA currents of lamina II neurons ( $n=13$ neurons in the control group, $n=14$ neurons in the PMA group; $F_{(3,52)}=10.02, p=0.0004$; Fig. $4 A, B)$. However, in $\alpha 2 \delta-1 \mathrm{KO}$ mice, treatment with PMA failed to significantly increase the amplitude of puff NMDA currents of lamina II neurons ( $n=15$ neurons in the control group, $n=$ 14 neurons in the PMA group; Fig. $4 A, B$ ).

To determine whether $\alpha 2 \delta-1$ is required for the PKC-activation-induced increase in synaptic trafficking of native NMDARs in the spinal cord, we isolated synaptosomes from the dorsal spinal cords of WT and $\alpha 2 \delta-1 \mathrm{KO}$ mice and then treated them with PMA or vehicle. Immunoblotting showed that treatment with PMA caused a large increase in the protein levels of both GluN1 and $\alpha 2 \delta-1$ in spinal cord synaptosomes in WT mice $(n=11$ mice per group; Fig. $4 C, D)$. In contrast, treatment with PMA had no significant effect on the GluN1 protein levels in spinal cord synaptosomes from $\alpha 2 \delta-1 \mathrm{KO}$ mice $(n=8$ mice per group, Fig. 4C,D). These findings demonstrate that $\alpha 2 \delta-1$ is indispensable for PKC-activationinduced potentiation of NMDAR activity and synaptic trafficking in the spinal cord.

The $\alpha \boldsymbol{2} \delta$-1-NMDAR interaction is dynamically controlled by PKC activity

Phosphorylation is an important regulator of many protein-protein interactions (Nishi et al., 2011). We have shown that inhibition of calcineurin, a protein phosphatase, increases the physical interaction between $\alpha 2 \delta-1$ and NMDARs in the spinal cord (Huang et al., 2020). We conducted coimmunoprecipitation analyses to determine whether PKC activation affects the physical interaction between $\alpha 2 \delta-1$ and GluN1. In HEK293 cells cotransfected with GluN1/GluN2A and $\alpha 2 \delta-1$, treatment with $1 \mu \mathrm{M}$ PMA significantly increased the amount of $\alpha 2 \delta$-1 proteins precipitated by an anti-GluN1 antibody $\left(n=8\right.$ independent experiments; $F_{(3,28)}$ $=24.47, p=0.0009$; Fig. 5A,B). Furthermore, treatment with Gö6983 significantly reduced the amount of $\alpha 2 \delta$-1 proteins precipitated by an anti-GluN1 antibody $(n=8$ independent experiments; $F_{(3,28)}=24.47, p=0.0314$; Fig. $\left.5 A, B\right)$. In the presence of Gö6983, PMA had no significant effect on the amount of $\alpha 2 \delta$ 1 -GluN1 protein complexes $(n=8$ independent experiments; Fig. 5A,B).

We then used Duolink PLA as an alternative approach to determine the role of PKC activity in the $\alpha 2 \delta-1$ interaction with NMDARs in HEK293 cells transfected with GluN1/GluN2A and $\alpha 2 \delta$-1. PLA allows detection of protein-protein interactions in situ when two target proteins are in close proximity (typically within 30-40 nm; Söderberg et al., 2008; Pacchiana et al., 2014), and this is accomplished using antibodies identifying the two proteins (epitopes) of interest followed by specific DNA primers covalently linked to the antibodies. A hybridization step followed by DNA amplification with fluorescent probes permits visualization of signals of proximity by fluorescence microscopy. In HEK293 cells treated with the vehicle, $\alpha 2 \delta-1-$ GluN1 interaction signals, shown as distinct bright punctate, were readily detected on plasma membranes and in intracellular compartments (Fig. $5 C, D$ ).
Treatment with $1 \mu \mathrm{M}$ PMA markedly increased the $\alpha 2 \delta$-1GluN1 interaction signal on the cell surface and in the intracellular space. In contrast, treatment with $1 \mu \mathrm{M}$ Gö6983 largely diminished the $\alpha 2 \delta-1-$ GluN1 interaction signal present in HEK293 cells $(n=6$ independent experiments per group; Fig. $5 C, D$ ). These results provide strong evidence for the critical role of PKC activity in promoting the $\alpha 2 \delta$-1-NMDAR physical interaction.

\section{$\alpha \boldsymbol{\alpha} \delta$-1-bound NMDARs are responsible for PKC-activation- induced increases in NMDAR activity}

To further determine whether $\alpha 2 \delta$-1 is required for the potentiation of NMDAR activity by PKC activation, we examined the effect of pregabalin, a clinically used $\alpha 2 \delta-1$ inhibitory ligand (Bian et al., 2006), on PMA-induced receptor activity in HEK293 cells coexpressing GluN1/GluN2A and $\alpha 2 \delta-1$. Treatment with $20 \mu \mathrm{M}$ pregabalin for $30 \mathrm{~min}$ blocked the potentiating effect of PMA on the current density ( $n=16$ cells in the PMA group, $n=$ 12 cells in the PMA+pregabalin group; Fig. $6 A, B)$.

Next, we determined whether the $\alpha 2 \delta$-1-NMDAR interaction is required for PMA-induced increases in NMDAR activity. Because $\alpha 2 \delta-1$ mainly interacts with NMDARs via its C terminus, we developed a 30-amino-acid peptide mimicking the C-terminal domain of $\alpha 2 \delta-1$ fused with Tat protein, termed $\alpha 2 \delta$ 1 Tat peptide (Chen et al., 2018). We have previously shown that $\alpha 2 \delta$-1Tat peptide effectively disrupts the $\alpha 2 \delta$-1-NMDAR interaction in vitro and in vivo (Chen et al., 2018; Luo et al., 2018; Huang et al., 2020). In HEK293 cells coexpressing GluN1/ 

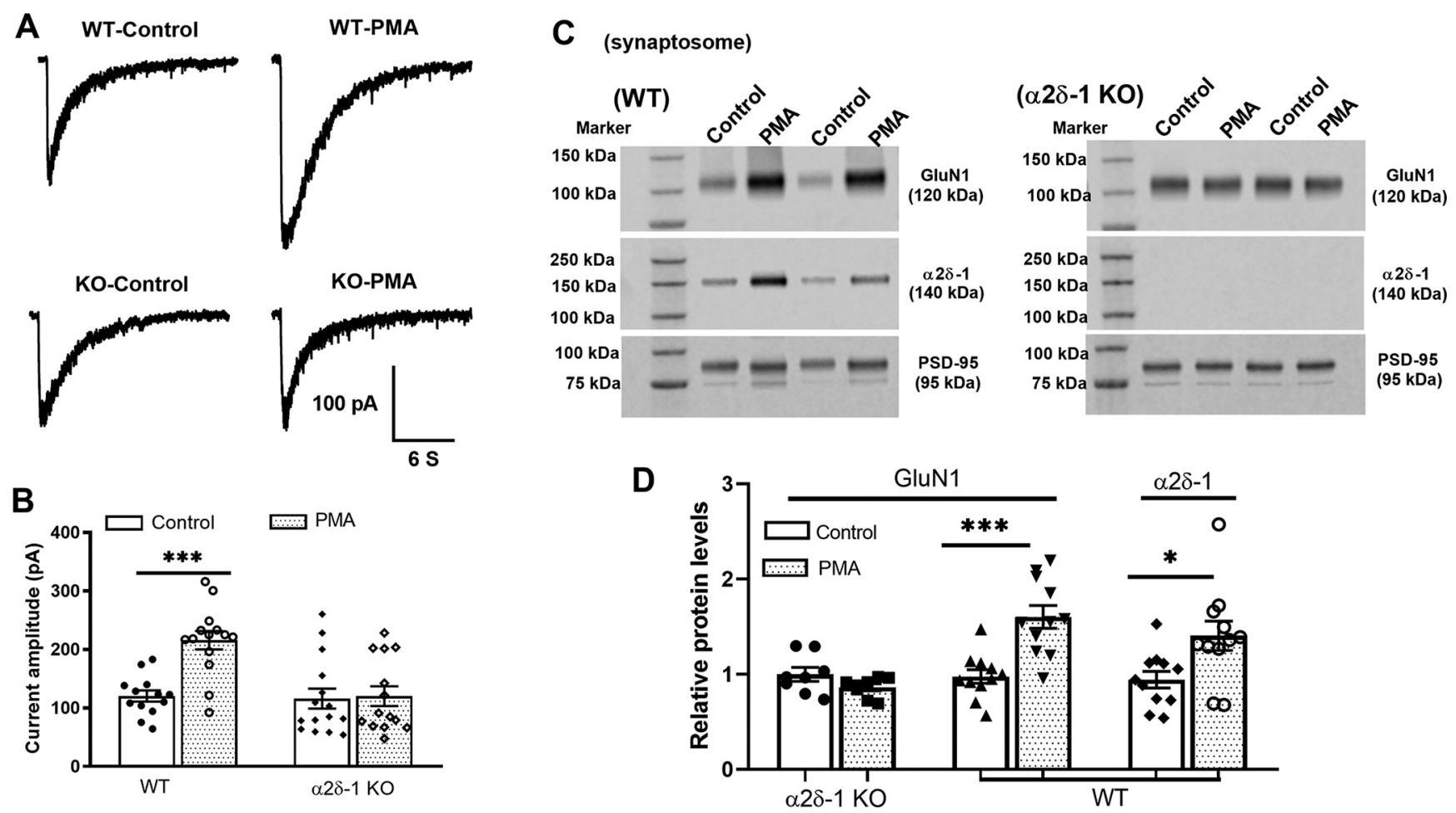

Figure 4. $\alpha 2 \delta-1$ is essential for PKC activation-induced potentiation of the activity and synaptic trafficking of NMDARs in the spinal cord. $\boldsymbol{A}, \boldsymbol{B}$, Original current traces $(\boldsymbol{A})$ and mean data (B) show the differential effect of PMA treatment $(1 \mu \mathrm{m}$ for $30 \mathrm{~min}$ ) on currents elicited by puff application of $100 \mu \mathrm{m}$ NMDA to spinal dorsal horn neurons in WT mice ( $n=13$ neurons from 4 mice in the control group, $n=14$ neurons from 4 mice in the PMA group) and $\alpha 2 \delta-1 \mathrm{KO}$ mice ( $n=15$ neurons from 4 mice in the control group, $n=14$ neurons from 4 mice in the PMA group). $\boldsymbol{C}, \boldsymbol{D}$, Representative blotting images ( $\boldsymbol{C}$; two pairs of samples) and quantification $(\boldsymbol{D})$ of the protein levels of GluN1 and $\alpha 2 \delta-1$ in synaptosomes isolated from the mouse dorsal spinal cord. PSD-95, a synaptic protein, was used as the internal control for normalizing the protein level on the same gel. The spinal cord slices were incubated with vehicle control or $1 \mu \mathrm{m}$ PMA for 30 min ( $n=8$ mice in the $\alpha 2 \delta$-1 K0 group, $n=11$ mice in the WT group) immediately before synaptosome isolation. Data are expressed as means \pm SEM. ${ }^{*} p<0.05$, ${ }^{* * *} p<0.001$ versus vehicle control (one-way ANOVA followed by Tukey's post hoc test).

GluN2A and $\alpha 2 \delta$-1, treatment with $\alpha 2 \delta$-1Tat peptide $(1 \mu \mathrm{M}$ for $30 \mathrm{~min})$ blocked the potentiating effect of PMA on current density $(n=12$ cells; Fig. $6 A, B)$. In contrast, treatment with a Tatfused scrambled control peptide $(1 \mu \mathrm{M}$ for $30 \mathrm{~min})$ did not significantly alter the stimulating effect of PMA on the current density $(n=11$ cells; Fig. $6 A, B)$.

Additionally, coimmunoprecipitation showed that treatment with PMA caused a large increase in the amount of $\alpha 2 \delta$ 1 proteins precipitated by an anti-GluN1 antibody ( $n=7$ independent experiments; $F_{(4,30)}=5.558, p=0.0018$; Fig. $\left.6 C, D\right)$. Furthermore, treatment with pregabalin or $\alpha 2 \delta$-1Tat peptide diminished the potentiating effect of PMA on the $\alpha 2 \delta-1-$ GluN1 complexes in HEK293 cells coexpressing GluN1/ GluN2A and $\alpha 2 \delta-1$ ( $n=7$ independent experiments; Fig. $6 C$, $D)$. These findings consistently indicate that PKC activation potentiates NMDAR activity predominantly through $\alpha 2 \delta-1$ bound NMDARs.

\section{S929 on GluN2A and S1413 on GluN2B are critically involved in NMDAR activity potentiated by PKC activation and $\alpha 2 \delta$-1}

Phosphorylation is a fundamental mechanism that regulates NMDAR activity and trafficking, and the C termini of NMDARs are the major substrates of PKC (Gardoni et al., 2001; Krupp et al., 2002). PKC activation increases the activity of NMDARs containing GluN2A or GluN2B subunits, but not GluN2C or GluN2D subunits (Mori et al., 1993; Wagner and Leonard, 1996; Grant et al., 2001). In contrast, PKC phosphorylation sites in GluN1 are not required for PKC potentiation of NMDAR currents (Yamakura et al., 1993). To identify the key phosphorylation sites of NMDARs that are involved in $\alpha 2 \delta$-1-mediated and PKC-activation-mediated potentiation of NMDAR activity, we used the unbiased quantitative proteomic method of SILAC to identify the phosphorylated sites of C termini of NMDAR subunits and $\alpha 2 \delta-1$ upregulated by PKC activity in HEK293 cells. Five putative phosphopeptides that were potentially altered by treatment with PMA and Gö6983 were identified. The putative phosphorylation sites were S929 on GluN2A and S940, S1159, S1303, and S1413 on GluN2B (Fig. 7). Compared with those of the corresponding proteins, the heavy/light ratios of these putative phosphopeptides were increased (Fig. 8; Table 1). We also identified putative phosphorylation sites of Y251, S262, Y943, and S944 on GluN2A, S1323 and T1408 on GluN2B, and S249 on $\alpha 2 \delta-1$. However, they were not considered for further investigation because of ambiguity in site assignment (Y943 or S944 on GluN2A), lack of increased heavy/light ratios compared with those of the whole protein (Y251 and S262 on GluN2A; S1323 and T1408 on GluN2B), or a limited number of identified protein peptides for heavy/light ratio comparison (S249 on $\alpha 2 \delta-1$ ). Except for S1303 on GluN2B, we considered the identified phosphorylation sites to be mostly putative because of a low Mascot score $(<20$; Table 1$)$. No significant putative phosphopeptides of GluN1 were identified.

We next used point mutations, replacing serine with alanine, to determine the role of $\$ 929$ in regulating GluN2A-containing NMDAR activity induced by PKC activity and $\alpha 2 \delta-1$. For this mutagenesis experiment, we selected $\mathrm{S} 917$ on GluN2A as a control. Mutation of S929 or S917 on GluN2A led to a significant reduction in the basal current density, compared with GluN2A- 
A (GluN1/GluN2A/ $2 \delta-1)$

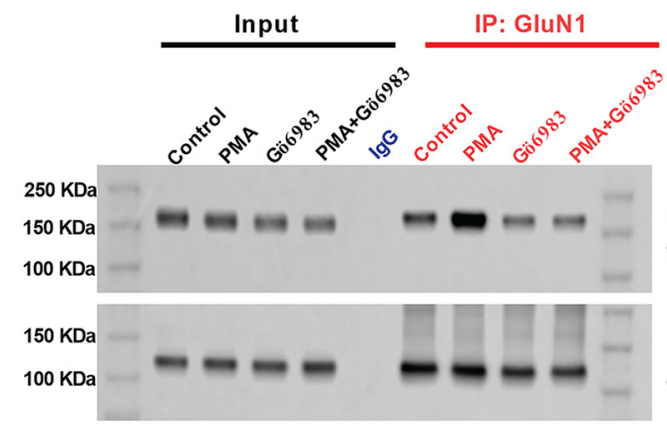

B ( $(\alpha 2 \delta-1-$ GluN1)

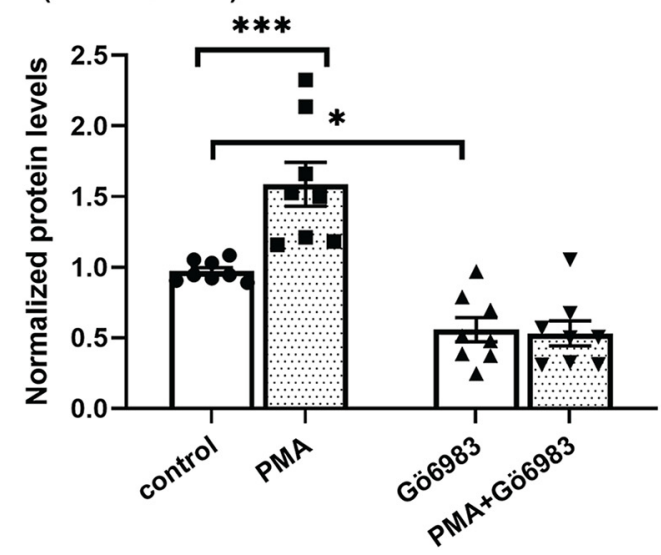

C

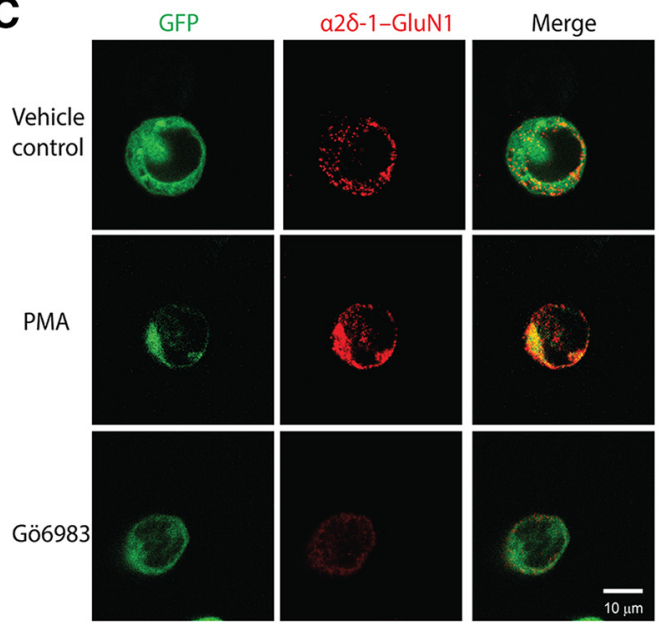

D

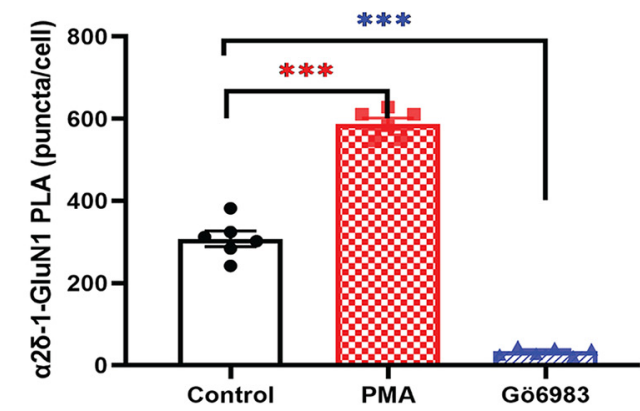

Figure 5. The $\alpha 2 \delta$-1-NMDAR interaction is controlled by PKC activity. $\boldsymbol{A}, \boldsymbol{B}$, Representative blotting images $(\boldsymbol{A})$ and mean data $(\boldsymbol{B})$ show the effect of treatment with $1 \mu \mathrm{m}$ PMA, $1 \mu \mathrm{M}$ Gö6983 or both on the interaction between $\alpha 2 \delta$-1 and GluN1 in HEK293 cells expressing $\alpha 2 \delta-1$ and V5-tagged GluN1/GluN2A ( $n=8$ independent experiments). Proteins were immunoprecipitated (IP) initially with a rabbit anti-GluN1 antibody or IgG. Immunoblotting was then performed using mouse anti- $\alpha 2 \delta-1$ or mouse anti-V5 antibodies. The $\alpha 2 \delta-1$ and GluN1 protein levels were normalized by input on the same gel. $\boldsymbol{C}, \boldsymbol{D}$, Representative PLA images $(\boldsymbol{C})$ and quantification $(\boldsymbol{D} ; n=6$ independent experiments) show the effect of treatment with $1 \mu \mathrm{m}$ PMA or 1 $\mu \mathrm{m}$ Gö6983 on the $\alpha 2 \delta$-1-GluN1 interaction signals (red) in HEK293 cells transfected with GluN1/GluN2A and $\alpha 2 \delta$-1-GFP (green). Data are expressed as means \pm SEM. * $p<0.05$, ${ }^{* * *} p<0.001$ versus the vehicle control group (one-way ANOVA followed by Tukey's post hoc test).

WT (Fig. 9). Treatment with $1 \mu \mathrm{M}$ PMA still significantly increased the receptor current in HEK293 cells cotransfected with GluN2A-S917A mutant and $\alpha 2 \delta-1$ ( $n=13$ cells in the control group, $n=12$ cells in the PMA group; $F_{(2,35)}=13.98, p=$ 0.0125; Fig. 9). Also, the potentiating effect of PMA was blocked by $1 \mu \mathrm{M}$ Gö6983. However, in HEK293 cells cotransfected with GluN1/S929A mutant and $\alpha 2 \delta$-1, treatment with PMA did not significantly affect the receptor current $(n=14$ cells in the control group, $n=11$ cells in the PMA group; Fig. 9).

We then attempted to determine which of the four putative phosphorylation sites of GluN2B, identified by MS, plays a significant role in $\alpha 2 \delta$-1-coexpression-induced potentiation of GluN2B-containing NMDAR activity. Compared with currents reconstituted with GluN1/GluN2B-WT, expression of GluN1/ GluN2B-S1303A mutant caused a large reduction in the basal receptor current ( $n=13$ cells in the GluN1/GluN2B-WT group, $n=14$ cells in the GluN1/GluN2B-S1303A group; $F_{(3,52)}=18.32$, $p=0.0048$; Fig. $10 A, B)$. However, coexpression with $\alpha 2 \delta$-1 still significantly increased the receptor current of HEK293 cells transfected with GluN1/GluN2B-S1303A mutant $(n=14$ cells in the GluN1/GluN2B-S1303A group, $n=16$ cells in the GluN1/ GluN2B-S1303A $+\alpha 2 \delta$-1 group; $F_{(3,52)}=18.32, p=0.0304$; Fig. $10 A, B)$. Furthermore, mutation of S940, S1159, and S1413 on GluN2B did not significantly alter the basal receptor current, compared with the GluN2B-WT group. Replacing GluN2B-
WT with S1413A mutant, but not S940A or S1159A mutant, abolished the $\alpha 2 \delta$-1-coexpression-induced increase in the current reconstituted with GluN1/GluN2B (Fig. 10A,B). Together, these findings indicate that $\$ 929$ on GluN2A and S1413 on GluN2B are the key phosphorylation sites of NMDARs involved in regulating NMDAR activity induced by PKC and $\alpha 2 \delta-1$.

\section{Discussion}

The major challenge in studies of NMDAR phosphorylation is to define the functional significance of each phosphorylation event and demonstrate how multiple signaling cascades are coordinated in response to neuronal activity to shape synaptic plasticity. In this study, we specifically determined the relationship between protein phosphorylation and protein-protein interactions in the context of NMDAR regulation. PKC has long been implicated in the regulation of synaptic plasticity by phosphorylating transporters, ion channels, and G-proteincoupled receptors, and PKC is typically activated by increases in the concentration of diacylglycerol and intracellular calcium (Oancea and Meyer, 1998; Callender and Newton, 2017). We showed that $\alpha 2 \delta$-1 was indispensable for PKC-activationinduced trafficking and activity of NMDARs and that the $\alpha 2 \delta$-1-NMDAR interaction was controlled by PKC-mediated phosphorylation. Strikingly, PKC-induced phosphorylation or $\alpha 2 \delta$-1 alone had little effect on NMDAR activity. Our findings 
A (GluN1/2A/ $2 \delta-1)$

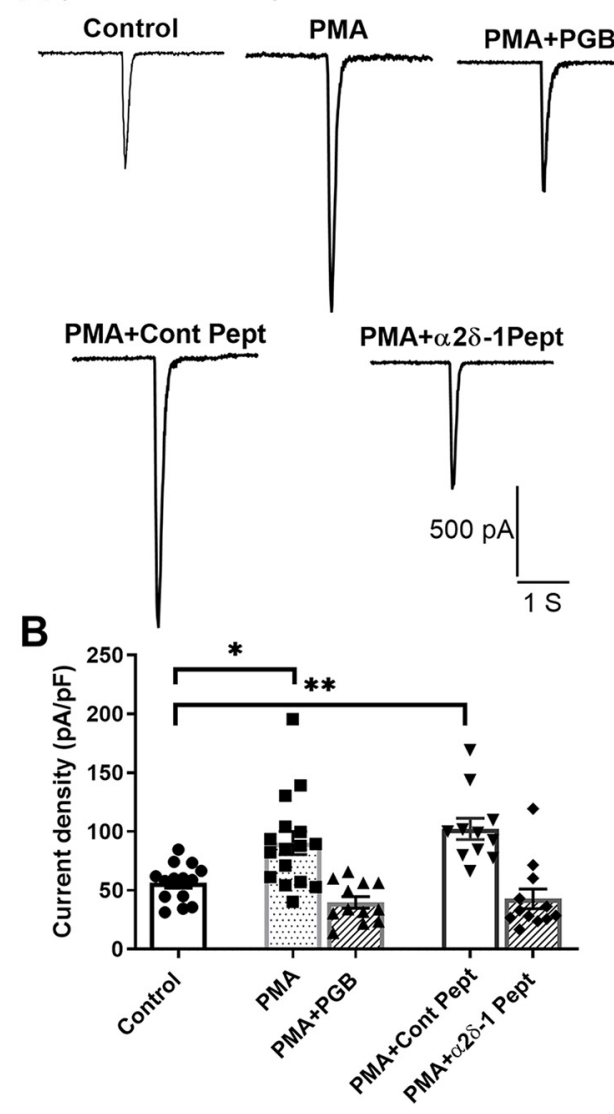

C (GluN1/2A/ $\alpha 2 \delta-1)$
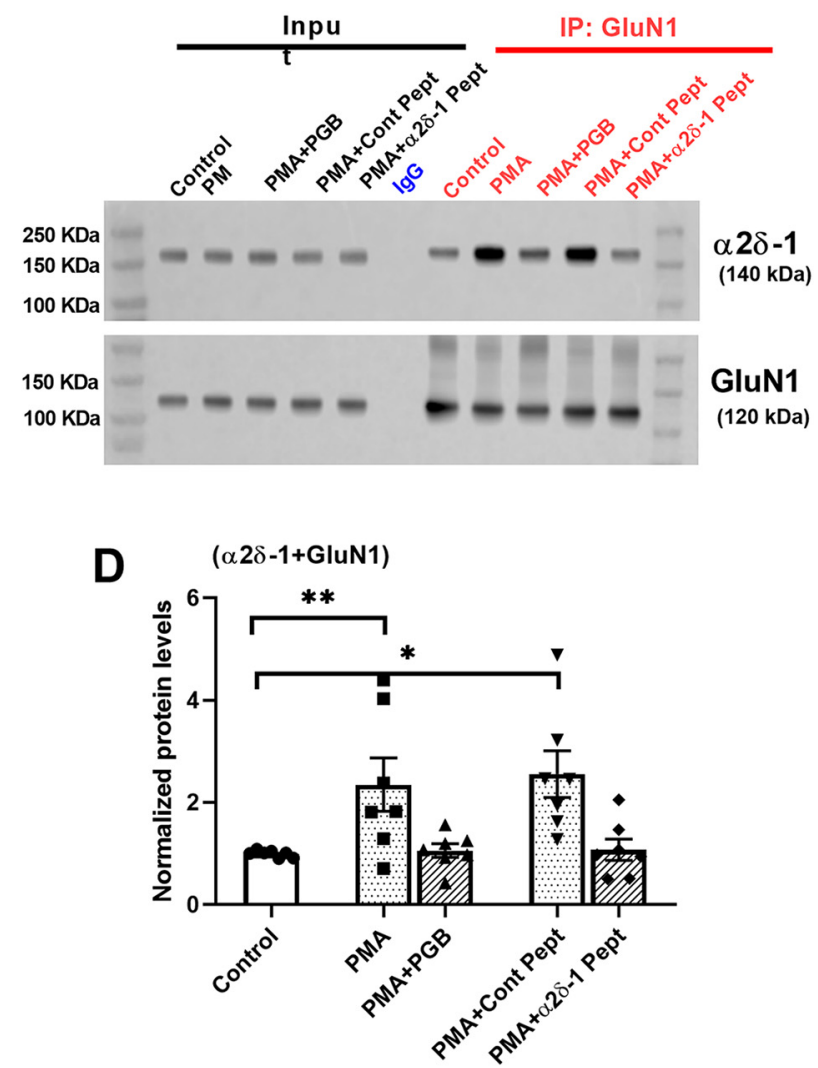

Figure 6. PKC regulates NMDAR activity primarily through $\alpha 2 \delta$-1-bound NMDARs. $\boldsymbol{A}, \boldsymbol{B}$, Original current traces $(\boldsymbol{A})$ and mean changes $(\boldsymbol{B})$ show the effect of treatment with $20 \mu \mathrm{m}$ pregabalin (PGB) or $1 \mu \mathrm{m} \alpha 2 \delta$-1Tat peptide ( $\alpha 2 \delta$-1 Pept), or $1 \mu \mathrm{m}$ control peptide (Cont Pept) on PMA-induced increases in NMDAR currents elicited by NMDA (300 $\mu \mathrm{m}$ for $5 \mathrm{~ms}$ ) in HEK293 cells expressing GluN1/GluN2A plus $\alpha 2 \delta-1$ ( $n=14$ cells in the control group, $n=16$ cells in the PMA group, $n=12$ cells in the PMA+PGB group, $n=11$ cells in the PMA + Cont Pept group, and $n=12$ cells in the PMA $+\alpha 2 \delta$-1 Pept group). C, $\mathbf{D}$, Representative blotting images (C) and mean data (D) show the effect of treatment with $20 \mu \mathrm{m}$ PGB, $1 \mu \mathrm{m} \alpha 2 \delta$-1Tat peptide $(\alpha 2 \delta$-1 Pept), or $1 \mu \mathrm{m}$ control peptide (Cont Pept) on the PMA-induced $\alpha 2 \delta$-1-GluN1 interaction in HEK293 cells expressing $\alpha 2 \delta$ - 1 and V5-tagged GluN1/GluN2A ( $n=7$ independent experiments). Proteins were immunoprecipitated (IP) initially with a rabbit anti-GluN1 antibody or lgG. Immunoblotting was then performed using mouse anti- $\alpha 2 \delta$-1 or mouse anti-V5 antibodies. Input was used as the internal control for normalization on the same gel. Data are expressed as means \pm SEM. ${ }^{*} p<0.05,{ }^{* *} p<0.01$ versus the vehicle control group (one-way ANOVA followed by Tukey's post hoc test).

thus provide a molecular framework for understanding the interplay between protein phosphorylation and protein-protein interactions.

The most salient finding of our study is that $\alpha 2 \delta-1$ is essential for PKC-activation-induced potentiation of NMDAR activity. PKC is involved in diverse cellular signaling pathways in the nervous system and is a key regulator of NMDARs (Ben-Ari et al., 1992; Chen and Roche, 2007). PKC at the spinal cord level plays a major role in chronic pain and opioidinduced tolerance and hyperalgesia (Coderre, 1992; Mao et al., 1994; Zhao et al., 2012; Xie et al., 2017b). Similarly, $\alpha 2 \delta-1$ is required for NMDAR activity potentiated in these conditions (Chen et al., 2018, 2019; Deng et al., 2019). Gabapentinoids, the $\alpha 2 \delta-1$ inhibitory ligands, attenuate neurotransmitter release in the trigeminal nucleus and spinal cord caused by PKC activation but have no such effects in normal tissues (Maneuf and McKnight, 2001; Fehrenbacher et al., 2003), again suggesting a potential link between $\alpha 2 \delta-1$ and PKCmediated signaling. The exact molecular mechanisms underlying the activity-dependent trafficking of NMDARs during the development of synaptic plasticity are not fully understood. Previous studies on NMDAR regulation by protein kinases were done mostly using brain tissues, cultured neurons, and neuronal cell lines with endogenous $\alpha 2 \delta-1$ expression
(Chen and Roche, 2007; Chen et al., 2014a,b; Lussier et al., 2015), which likely masked the crucial role of $\alpha 2 \delta-1$ in regulating NMDARs by phosphorylation. We showed that PKC activation or inhibition affected NMDAR activity and surface expression in HEK293 cells only in the presence of $\alpha 2 \delta-1$. We also found that PKC stimulation potentiated NMDAR activity and synaptic trafficking in the spinal cord in WT mice, but not in $\alpha 2 \delta-1 \mathrm{KO}$ mice. In addition, pregabalin or $\alpha 2 \delta-1 \mathrm{C}$ terminus blocking peptide abolished the effect of PKC stimulation on NMDAR activity. Together, these findings consistently support the notion that $\alpha 2 \delta-1$ is an essential regulator in PKC-phosphorylation-induced NMDAR activity and that $\alpha 2 \delta$-1bound NMDARs primarily mediate the surface/synaptic trafficking of NMDARs elicited by PKC activation (Fig. 10C).

We found in the current study that PKC activation with PMA further increased the $\alpha 2 \delta$-1-induced enhancement of GluN2Acontaining receptor activity. However, PMA did not potentiate the activity of GluN2B-containing receptors that was already augmented by $\alpha 2 \delta-1$ coexpression. Nevertheless, expressing $\alpha 2 \delta-1$ with GluN1/GluN2A or GluN1/GluN2B led to a large increase in receptor activity, which was reversed by the PKC inhibitor. Different NMDAR subunits may preferentially couple receptors to distinct intracellular signaling complexes. For example, GluN2B bound to active CaMKII is much stronger than 

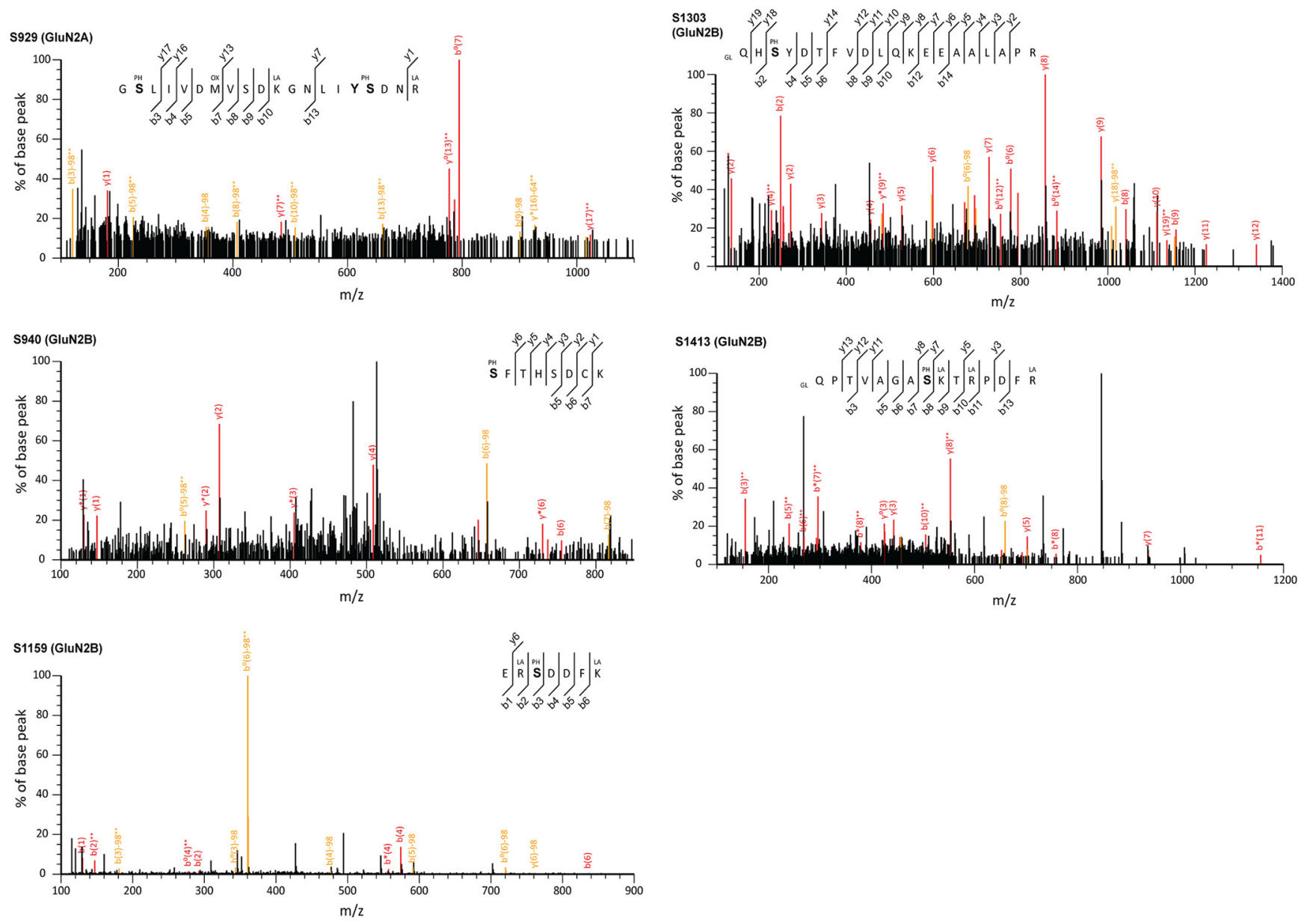

Figure 7. Annotated spectra of fragmented ions (tandem mass spectrometry) of putative GluN2A and GluN2B phosphopeptides. The phosphorylation sites and peptide sequences are indicated. Only $b$ and $y$ ions, whose matches were qualified and used for scoring by Mascot version 2.7, are labeled. PH, Phosphorylation $(S, T, Y) ; 0 X, 0 x i d a t i o n(M) ; L A,{ }^{13} C(6), K, R ; G L$, $\mathrm{Gln} \rightarrow$ pyro-Glu (N-term Q); Annotation: b, B-ion; $\mathrm{y}$, y-ion; number, position of fragmentation; ${ }^{*}$ loss of an ammonia; ${ }^{\circ}$ loss of a water; ${ }^{++}$double charge; -98 , neutral loss of $\mathrm{H}_{3} \mathrm{PO}_{4}$.

GluN2A (Strack and Colbran, 1998). It is possible that GluN2Bcontaining NMDARs are sufficiently phosphorylated by constitutive PKC activity when expressed in HEK293 cells, thus allowing $\alpha 2 \delta-1$ to interact more readily with GluN2B than with GluN2A.

Another major finding of our study is that PKC-mediated phosphorylation dynamically controls the $\alpha 2 \delta$-1-NMDAR physical interaction. Protein phosphorylation is one of the most common and important post-translational modifications, which control intracellular trafficking and localization of proteins via regulation of many protein-protein interactions (Sacco et al., 2012; Li et al., 2013). Using coimmunoprecipitation and PLA assays, we showed that PKC stimulation increased the $\alpha 2 \delta$ 1-NMDAR association, whereas PKC inhibition diminished the $\alpha 2 \delta-1-\mathrm{NMDAR}$ protein complex, supporting the notion that $\alpha 2 \delta-1$ mainly functions as a phospho-binding protein. Furthermore, pregabalin or $\alpha 2 \delta-1 \mathrm{C}$ terminus blocking peptide eliminated the potentiating effect of the PKC activator on the $\alpha 2 \delta-1-\mathrm{NMDAR}$ interaction. These findings suggest that the $\alpha 2 \delta-1-\mathrm{NMDAR}$ interaction is dynamic and critically depends on PKC-mediated NMDAR phosphorylation. Calcineurin inhibition increases the $\alpha 2 \delta$-1-NMDAR physical interaction and synaptic trafficking in the spinal cord (Huang et al., 2020), also supporting a role for protein phosphorylation in regulating the $\alpha 2 \delta$-1-NMDAR interaction. Phosphorylation regulates protein function and cell signaling by causing allosteric changes in the phosphorylated protein. The addition of a phosphate group $\left(\mathrm{PO}_{4}\right)$ can introduce new electrostatic interactions and modify the protein from hydrophobic apolar to hydrophilic polar, allowing the protein to change conformation when interacting with other proteins (Nishi et al., 2011; Ardito et al., 2017). $\alpha 2 \delta-1$ interacts only with functional NMDARs because it does not bind to GluN1, GluN2A, or GluN2B when these subunits are expressed alone with $\alpha 2 \delta-1$ in HEK293 cells (Chen et al., 2018). Our findings indicate that $\alpha 2 \delta$-1 largely functions as a phospho-binding protein and primarily couples to phosphorylated NMDARs (Fig. 10C). Under basal conditions, the $\alpha 2 \delta$-1-NMDAR interaction seems to be weak when NMDARs are minimally phosphorylated, which could explain why $\alpha 2 \delta-1$ was not identified as an NMDAR-interacting protein in previous proteomics studies (Husi et al., 2000; Frank et al., 2016) and why gabapentinoids have no effects on NMDAR activity or nociception under normal conditions (Chen et al., 2018, 2019; Deng et al., 2019; Huang et al., 2020). Because enhanced neuronal/ nerve activity often leads to PKC activation (Zhao et al., 2012; Xie et al., 2017a,b), it is likely that the interaction between $\alpha 2 \delta-1$ and NMDARs is controlled on demand by neuronal and synaptic activity in vivo. It remains to be determined whether the $\alpha 2 \delta-1-$ NMDAR interaction is also subject to control by other protein kinases, including CK2, CaMKII, and Src, which can potentiate the phosphorylation and activity of NMDARs (Omkumar et al., 1996; 
S929 (GluN2A)

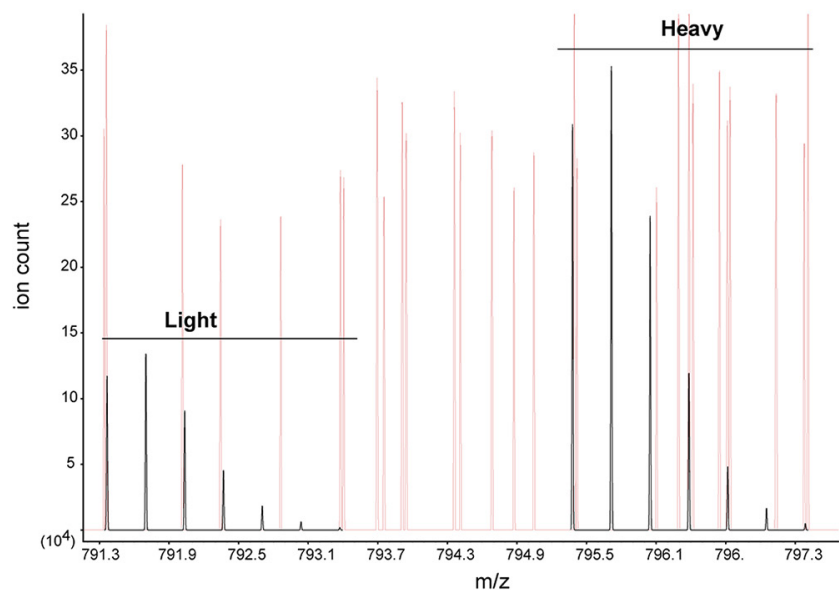

S1159 (GluN2B)

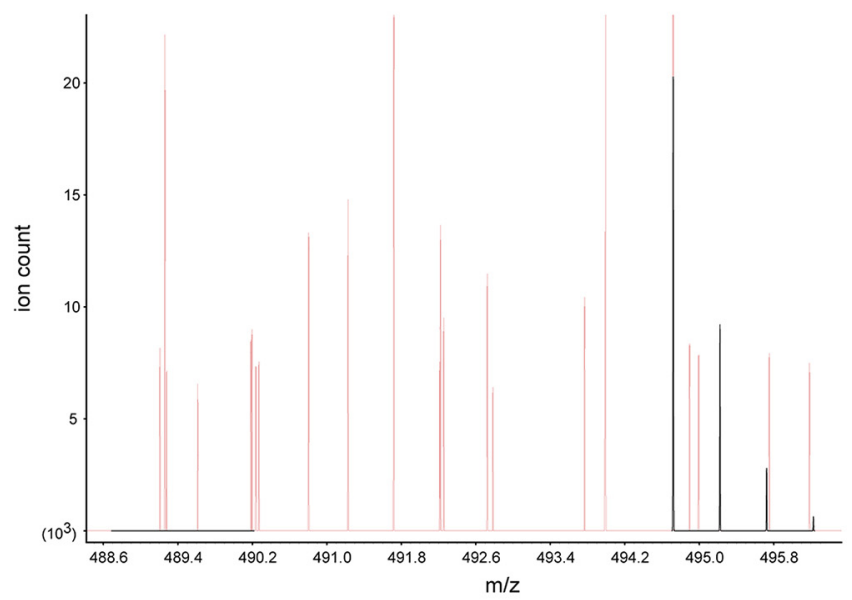

S1413 (GluN2B)

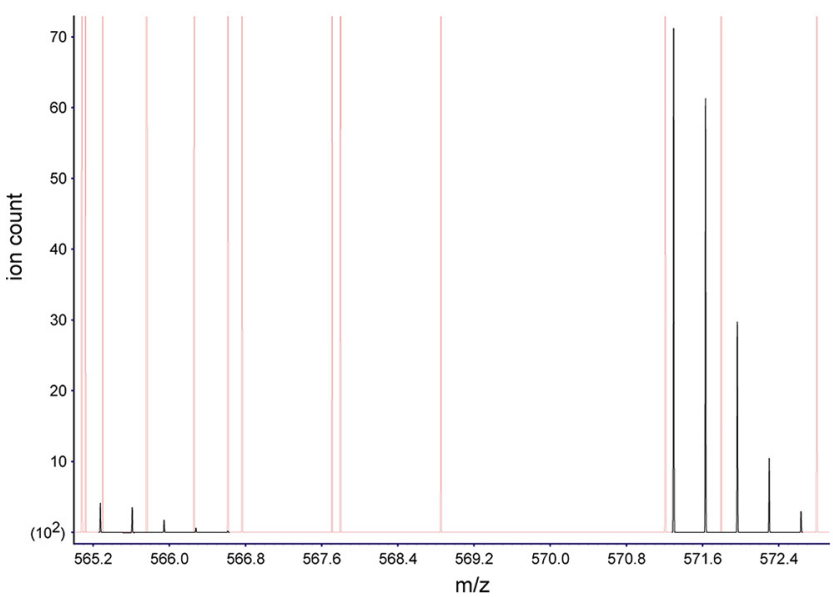

S940 (GluN2B)

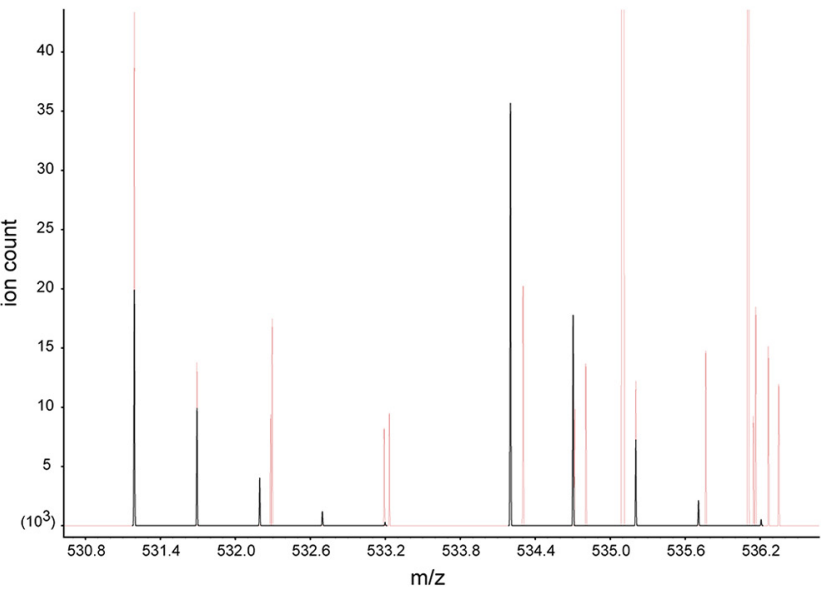

S1303 (GluN2B)

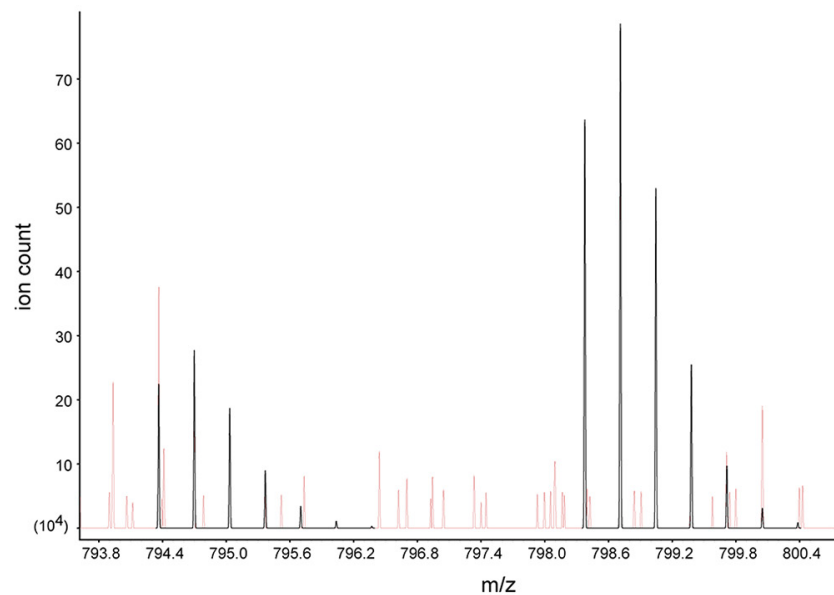

Figure 8. Light-heavy precursor isotopic ion (mass spectrometry) peak pairs (black) of putative phosphopeptides harboring the indicated phosphorylation sites. The specific phosphorylation sites on GluN2A and GluN2B are indicated on the top of each panel. The peptides correspond to those in Figure 7.

Chung et al., 2004; Salter and Kalia, 2004; Chen and Roche, 2007; Hu et al., 2014; Chen et al., 2014b).

Using unbiased quantitative phosphoproteomics and mutagenesis analyses, we identified S929 on GluN2A and S1413 on
GluN2B as the key phosphorylation sites for the control of $\alpha 2 \delta$ 1-bound NMDARs by PKC activity. Multiple serine, threonine, and tyrosine residues in the $\mathrm{C}$ termini of NMDAR subunits have been identified as phosphorylation sites by a set of synapse- 
Table 1. List of putative phosphopeptides identified by liquid chromatography-tandem mass spectrometry

\begin{tabular}{|c|c|c|c|c|c|c|c|}
\hline Protein & $\begin{array}{l}\text { Phosphorylation } \\
\text { site(s) }\end{array}$ & Peptide & Charge & $\begin{array}{l}\Delta \mathrm{Mr} . \\
\text { (ppm) }\end{array}$ & $\begin{array}{l}\text { Mascot } \\
\text { score }\end{array}$ & $\begin{array}{l}\mathrm{H} / \mathrm{L} \\
\text { (peptide) }\end{array}$ & $\begin{array}{l}\mathrm{H} / \mathrm{L} \\
\text { (protein) }\end{array}$ \\
\hline GluN2A & Y251, S262 & SLGLTGYDFFWIVPSLVSGNTELIPK & +3 & -5.28 & 18 & 0.4 & 1.6 \\
\hline GluN2A & S929, Y943/S944 & GSLIVDMVSDKGNLIYSDNR & +3 & 16.5 & 8 & 2.6 & 1.6 \\
\hline GluN2B & S1159 & ERSDDFK & +2 & 16.2 & 7 & $>10$ & 0.9 \\
\hline GluN2B & $\$ 1303$ & QHSYDTFVDLQK & +2 & -2.09 & 25 & 3.0 & 2.2 \\
\hline GluN2B & $\$ 1303$ & QHSYDTFVDLQKEEAALAPR & +3 & -1.31 & 49 & 2.8 & 2.2 \\
\hline GluN2B & T1408 & QPTVAGASKTR & +2 & -3.04 & 13 & $<0.1$ & 2.5 \\
\hline GluN2B & T1408, S1413 & QPTVAGASK & +2 & 18.9 & 6 & $<0.1$ & 0.9 \\
\hline GluN2B & S1413 & QPTVAGASKTRPDFR & +3 & 6.73 & 3 & $>10$ & 0.4 \\
\hline$\alpha 2 \delta-1$ & S249 & RPWYIQGAASPK & +3 & 14.4 & 11 & 3.4 & NA \\
\hline$\alpha 2 \delta-1$ & \$249 & RRPWYIQGAASPK & +3 & -13.9 & 14 & NA & NA \\
\hline
\end{tabular}

$\Delta$ Mr., Difference in the observed and calculated relative molecular mass; H/L, heavy/light ratio; NA, not available.
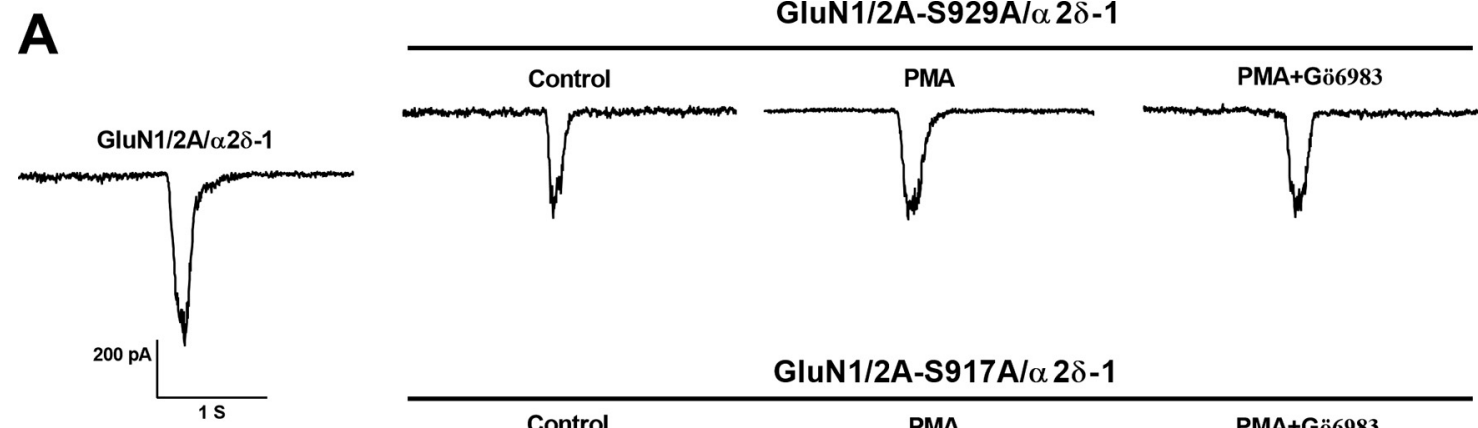

GluN1/2A-S929A/ $\alpha 2 \delta-1$

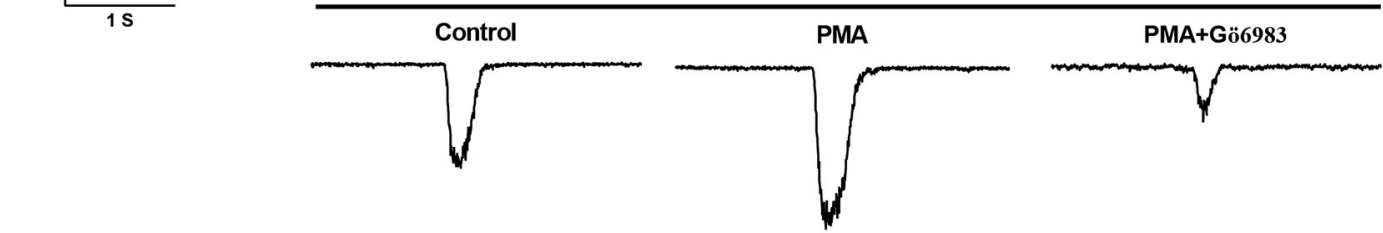

B

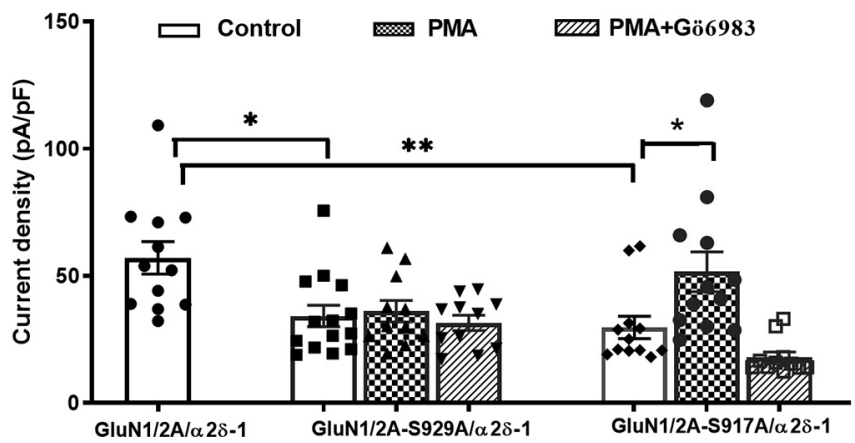

Figure 9. 5929 on GluN2A plays a role in PKC-activation-induced increases in GluN2A-containing NMDAR currents in the presence of $\alpha 2 \delta$-1. $\boldsymbol{A}, \boldsymbol{B}$, Original current traces $(\boldsymbol{A})$ and mean data (B) show the effect of treatment with $1 \mu \mathrm{m}$ PMA or $1 \mu \mathrm{m}$ Gö6983 on NMDAR currents elicited by NMDA (300 $\mu \mathrm{m}$ for $5 \mathrm{~ms}$ ) in HEK293 cells coexpressing $\alpha 2 \delta$-1 with GluN1/GluN2A-WT ( $n=$ 12 cells), GluN1/GluN2A-S929A ( $n=14$ cells in the control group, $n=11$ in the PMA group, $n=11$ cells in the PMA+Gö6983 group), or GluN1/GluN2A-S917A ( $n=13$ cells in the control group, $n=12$ cells in the PMA group, $n=13$ cells in the PMA + Gö6983 group). Data are expressed as means \pm SEM. ${ }^{*} p<0.05,{ }^{* *} p<0.01$ versus the GluN2A-WT or vehicle control group (one-way ANOVA followed by Tukey's post hoc test).

enriched protein kinases, including PKC (Tingley et al., 1997; Gardoni et al., 2001; Liao et al., 2001; Jones and Leonard, 2005). The C-terminal domain is the most divergent region of the NMDAR subunits and the most important substrate for phosphorylation (Chen and Roche, 2007; Warnet et al., 2020), and NMDAR synaptic localization and activity are mainly controlled by the C-terminal domain of GluN2 subunits (Mori et al., 1998; Sprengel et al., 1998; Cousins and Stephenson, 2012). Alaninescanning mutagenesis analysis suggests that S900 and S929 on GluN2A could be phosphorylated, although the relevant kinase is not identified (Krupp et al., 2002). Our proteomics and point mutation analyses indicate that $\mathrm{S} 929$ on GluN2A is important for PKC-activation-induced potentiation of $\alpha 2 \delta$-1-bound NMDARs. S929 seems to be also responsible for calcineurinmediated dephosphorylation of GluN2A (Krupp et al., 2002). Thus, calcineurin and PKC may mutually control GluN2A-containing NMDARs simply by altering the phosphorylation status of S929. Furthermore, our study showed that among the four 


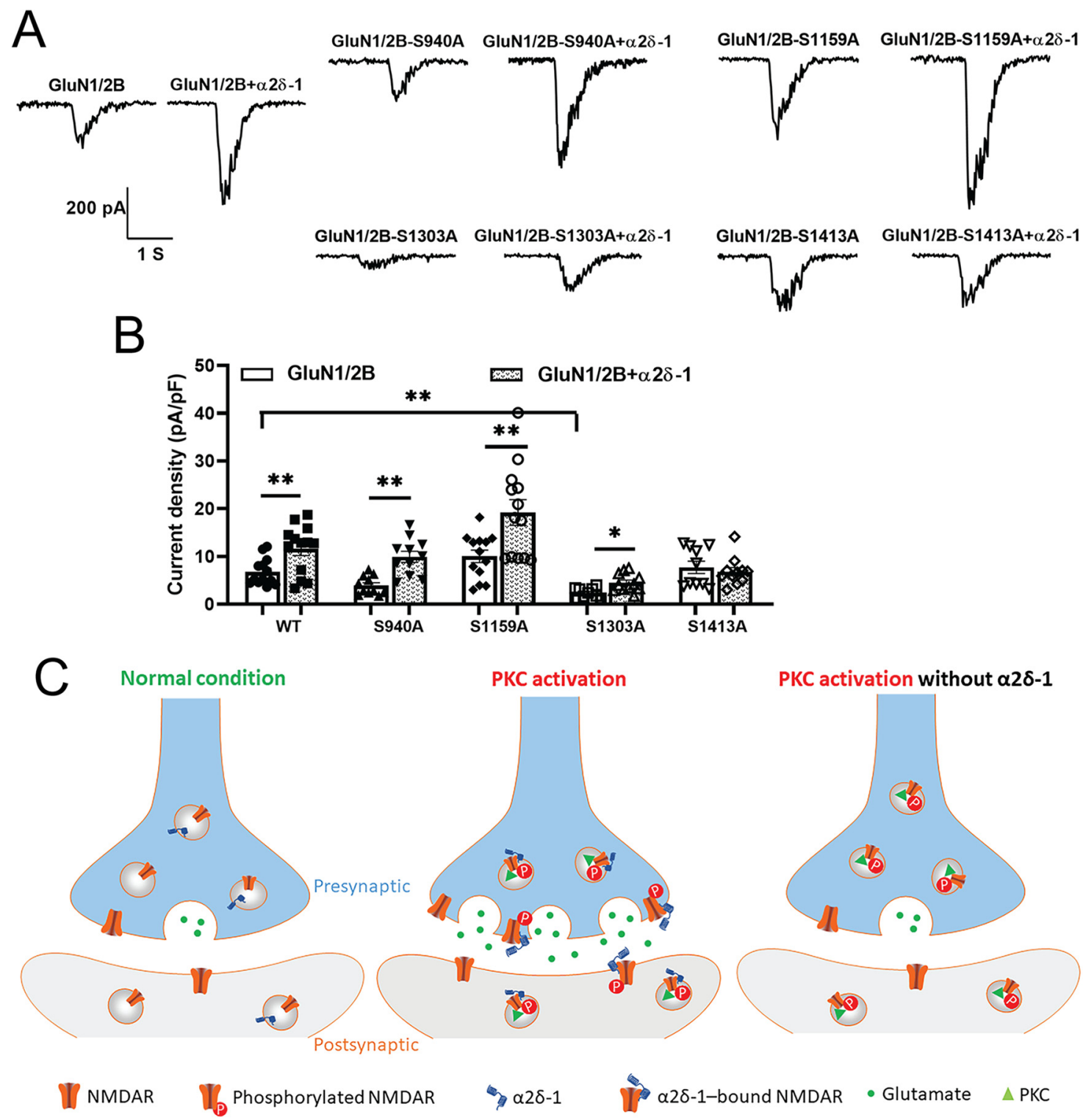

Figure 10. S1413 on GluN2B is important for $\alpha 2 \delta$-1-coexpression-induced increases in GluN2B-containing NMDAR currents. $\boldsymbol{A}, \boldsymbol{B}$, Original current traces $(\boldsymbol{A})$ and quantification $(\boldsymbol{B})$ show the effect of treatment with $1 \mu \mathrm{m}$ Gö6983 on NMDAR currents elicited by NMDA (300 $\mu \mathrm{m}$ for $5 \mathrm{~ms}$ ) in HEK293 cells expressing GluN1/GluN2B-WT or four separate GluN1/GluN2B mutants with and without $\alpha 2 \delta-1$ ( $n=13$ cells in the GluN1/GluN2B-WT group, $n=13$ cells in GluN1/GluN2B WT $+\alpha 2 \delta-1$ group, $n=11$ cells in the GluN1/Glun2B-S940A group, $n=11$ cells in GluN1/ GluN2B-S940A $+\alpha 2 \delta$-1 group, $n=13$ cells in the GluN1/GluN2B-S1159A group, $n=13$ cells in the GluN1/GluN2B-S1159A $+\alpha 2 \delta-1$ group, $n=14$ cells in the GluN1/GluN2B-S1303A group, $n=16$ cells in the GluN1/GluN2B-S1303A $+\alpha 2 \delta-1$ group, $n=10$ cells in the GluN1/GluN2B-S1413A group, $n=11$ cells in the GluN1/GluN2B-S1413A $+\alpha 2 \delta-1$ group). Data are expressed as means \pm SEM. ${ }^{*} p<0.05,{ }^{* *} p<0.01$ versus the GluN2B-WT or vehicle control group (one-way ANOVA followed by Tukey's post hoc test). C, Schematic showing the reciprocal role of $\alpha 2 \delta-1$ and PKC-mediated phosphorylation in regulating synaptic trafficking and activity of NMDARs. Under normal conditions, most intracellular NMDARs are unphosphorylated and are not associated with $\alpha 2 \delta$-1. When NMDARs are phosphorylated by PKC, $\alpha 2 \delta$-1 physically interacts with phosphorylated NMDARs and promotes synaptic trafficking of $\alpha 2 \delta$-1-NMDAR complexes, resulting in potentiated synaptic NMDAR activity. In the absence of $\alpha 2 \delta-1$ as an essential trafficking protein, phosphorylated NMDARs by PKC cannot reach presynaptic or postsynaptic sites.

initially identified PKC phosphorylation sites on GluN2B, only the $\mathrm{S} 1413 \mathrm{~A}$ mutant abolished the receptor activity potentiated by $\alpha 2 \delta-1$ coexpression. Sequence analysis of GluN2A and GluN2B suggests that S1303 and S1323 on GluN2B are putative PKC substrates (Liao et al., 2001). We found that although mutation of S1303 on GluN2B dramatically decreased receptor activity, $\alpha 2 \delta$ 1 coexpression still increased the activity of GluN2B-containing receptors. Intriguingly, S1413L (S1415L in humans, associated with autism) on GluN2B shows deficits in NMDAR trafficking, synaptic currents, and spine density (Liu et al., 2017), which also supports the notion that S1413 on GluN2B plays an important role in regulating NMDAR activity.
In conclusion, our study shows for the first time that PKC and $\alpha 2 \delta-1$ interdependently control NMDAR activity via the phosphorylation-dependent $\alpha 2 \delta$-1-NMDAR interaction. The $\alpha 2 \delta$-1-NMDAR interaction can occur promptly after NMDAR phosphorylation and PKC activation in the absence of increased availability of $\alpha 2 \delta-1$ proteins (e.g., upregulation). This information provides new mechanistic insight into the reciprocal roles of PKC-mediated phosphorylation and $\alpha 2 \delta$ 1 in regulating NMDARs in physiological and pathologic conditions and in the pharmacological actions of gabapentinoids (Chen et al., 2018; Luo et al., 2018; Ma et al., 2018; Zhou et al., 2018). Because PKC and $\alpha 2 \delta-1$ are widely 
coexpressed in the nervous system, this mechanism may be broadly involved in the induction and maintenance of synaptic plasticity in many disease processes. Therefore, targeting $\alpha 2 \delta$-1bound NMDARs may offer a new strategy for specifically inhibiting abnormally increased NMDAR activity to treat neuropathic pain and other neurologic disorders.

\section{References}

Ardito F, Giuliani M, Perrone D, Troiano G, Lo Muzio L (2017) The crucial role of protein phosphorylation in cell signaling and its use as targeted therapy (Review). Int J Mol Med 40:271-280.

Ben-Ari Y, Aniksztejn L, Bregestovski P (1992) Protein kinase C modulation of NMDA currents: an important link for LTP induction. Trends Neurosci 15:333-339.

Bian F, Li Z, Offord J, Davis MD, McCormick J, Taylor CP, Walker LC (2006) Calcium channel alpha2-delta type 1 subunit is the major binding protein for pregabalin in neocortex, hippocampus, amygdala, and spinal cord: an ex vivo autoradiographic study in alpha2-delta type 1 genetically modified mice. Brain Res 1075:68-80.

Bright R, Mochly-Rosen D (2005) The role of protein kinase C in cerebral ischemic and reperfusion injury. Stroke 36:2781-2790.

Butler AK, Uryu K, Chesselet MF (1998) A role for N-methyl-D-aspartate receptors in the regulation of synaptogenesis and expression of the polysialylated form of the neural cell adhesion molecule in the developing striatum. Dev Neurosci 20:253-262.

Callender JA, Newton AC (2017) Conventional protein kinase C in the brain: 40 years later. Neuronal Signal 1:Ns20160005.

Chen BS, Roche KW (2007) Regulation of NMDA receptors by phosphorylation. Neuropharmacology 53:362-368.

Chen L, Huang LY (1992) Protein kinase C reduces Mg2+ block of NMDAreceptor channels as a mechanism of modulation. Nature 356:521-523.

Chen J, Li L, Chen SR, Chen H, Xie JD, Sirrieh RE, MacLean DM, Zhang Y, Zhou MH, Jayaraman V, Pan HL (2018) The $\alpha 2 \delta$-1-NMDA receptor complex is critically involved in neuropathic pain development and gabapentin therapeutic actions. Cell Rep 22:2307-2321.

Chen SR, Hu YM, Chen H, Pan HL (2014a) Calcineurin inhibitor induces pain hypersensitivity by potentiating pre- and postsynaptic NMDA receptor activity in spinal cords. J Physiol 592:215-227.

Chen SR, Zhou HY, Byun HS, Chen H, Pan HL (2014b) Casein kinase II regulates N-methyl-D-aspartate receptor activity in spinal cords and pain hypersensitivity induced by nerve injury. J Pharmacol Exp Ther 350:301312 .

Chen Y, Chen SR, Chen H, Zhang J, Pan HL (2019) Increased $\alpha 2 \delta$-1NMDA receptor coupling potentiates glutamatergic input to spinal dorsal horn neurons in chemotherapy-induced neuropathic pain. J Neurochem 148:252-274.

Chohan MO, Iqbal K (2006) From tau to toxicity: emerging roles of NMDA receptor in Alzheimer's disease. J Alzheimers Dis 10:81-87.

Chung HJ, Huang YH, Lau LF, Huganir RL (2004) Regulation of the NMDA receptor complex and trafficking by activity-dependent phosphorylation of the NR2B subunit PDZ ligand. J Neurosci 24:10248-10259.

Coderre TJ (1992) Contribution of protein kinase C to central sensitization and persistent pain following tissue injury. Neurosci Lett 140:181-184.

Cole RL, Lechner SM, Williams ME, Prodanovich P, Bleicher L, Varney MA, Gu G (2005) Differential distribution of voltage-gated calcium channel alpha-2 delta (alpha2delta) subunit mRNA-containing cells in the rat central nervous system and the dorsal root ganglia. J Comp Neurol 491:246-269.

Collingridge GL, Bliss TV (1995) Memories of NMDA receptors and LTP. Trends Neurosci 18:54-56.

Cousins SL, Stephenson FA (2012) Identification of N-methyl-D-aspartic acid (NMDA) receptor subtype-specific binding sites that mediate direct interactions with scaffold protein PSD-95. J Biol Chem 287:13465-13476.

Deng M, Chen SR, Chen H, Pan HL (2019) $\alpha 2 \delta$-1-bound N-Methyl-D-aspartate receptors mediate morphine-induced hyperalgesia and analgesic tolerance by potentiating glutamatergic input in rodents. Anesthesiology 130:804-819.

Fehrenbacher JC, Taylor CP, Vasko MR (2003) Pregabalin and gabapentin reduce release of substance $\mathrm{P}$ and CGRP from rat spinal tissues only after inflammation or activation of protein kinase C. Pain 105:133-141.
Frank RA, Komiyama NH, Ryan TJ, Zhu F, O’Dell TJ, Grant SG (2016) NMDA receptors are selectively partitioned into complexes and supercomplexes during synapse maturation. Nat Commun 7:11264.

Fuller-Bicer GA, Varadi G, Koch SE, Ishii M, Bodi I, Kadeer N, Muth JN, Mikala G, Petrashevskaya NN, Jordan MA, Zhang SP, Qin N, Flores CM, Isaacsohn I, Varadi M, Mori Y, Jones WK, Schwartz A (2009) Targeted disruption of the voltage-dependent calcium channel alpha2/delta-1-subunit. Am J Physiol Heart Circ Physiol 297:H117-124.

Gardoni F, Bellone C, Cattabeni F, Di Luca M (2001) Protein kinase C activation modulates alpha-calmodulin kinase II binding to NR2A subunit of N-methyl-D-aspartate receptor complex. J Biol Chem 276:7609-7613.

George AA, Macleod GT, Zakon HH (2011) Calcium-dependent phosphorylation regulates neuronal stability and plasticity in a highly precise pacemaker nucleus. J Neurophysiol 106:319-331.

Grant ER, Guttmann RP, Seifert KM, Lynch DR (2001) A region of the rat $\mathrm{N}$-methyl-D-aspartate receptor $2 \mathrm{~A}$ subunit that is sufficient for potentiation by phorbol esters. Neurosci Lett 310:9-12.

Gschwendt M, Dieterich S, Rennecke J, Kittstein W, Mueller HJ, Johannes FJ (1996) Inhibition of protein kinase $\mathrm{C} \mathrm{mu}$ by various inhibitors. Differentiation from protein kinase $\mathrm{c}$ isoenzymes. FEBS Lett 392:77-80.

$\mathrm{Hu}$ YM, Chen SR, Chen H, Pan HL (2014) Casein kinase II inhibition reverses pain hypersensitivity and potentiated spinal N-methyl-D-aspartate receptor activity caused by calcineurin inhibitor. J Pharmacol Exp Ther 349:239-247.

Huang Y, Chen SR, Chen H, Luo Y, Pan HL (2020) Calcineurin inhibition causes $\alpha 2 \delta$-1-mediated tonic activation of synaptic NMDA receptors and pain hypersensitivity. J Neurosci 40:3707-3719.

Husi H, Ward MA, Choudhary JS, Blackstock WP, Grant SG (2000) Proteomic analysis of NMDA receptor-adhesion protein signaling complexes. Nat Neurosci 3:661-669.

Jones ML, Leonard JP (2005) PKC site mutations reveal differential modulation by insulin of NMDA receptors containing NR2A or NR2B subunits. J Neurochem 92:1431-1438.

Krupp JJ, Vissel B, Thomas CG, Heinemann SF, Westbrook GL (2002) Calcineurin acts via the $\mathrm{C}$-terminus of NR2A to modulate desensitization of NMDA receptors. Neuropharmacology 42:593-602.

Lan JY, Skeberdis VA, Jover T, Grooms SY, Lin Y, Araneda RC, Zheng X, Bennett MV, Zukin RS (2001) Protein kinase C modulates NMDA receptor trafficking and gating. Nat Neurosci 4:382-390.

Li DP, Zhu LH, Pachuau J, Lee HA, Pan HL (2014) mGluR5 Upregulation increases excitability of hypothalamic presympathetic neurons through NMDA receptor trafficking in spontaneously hypertensive rats. J Neurosci 34:4309-4317.

Li X, Wilmanns M, Thornton J, Köhn M (2013) Elucidating human phosphatase-substrate networks. Sci Signal 6:rs10.

Liao GY, Wagner DA, Hsu MH, Leonard JP (2001) Evidence for direct protein kinase-C mediated modulation of $\mathrm{N}$-methyl-D-aspartate receptor current. Mol Pharmacol 59:960-964.

Liu H, De Waard M, Scott VE, Gurnett CA, Lennon VA, Campbell KP (1996) Identification of three subunits of the high affinity omega-conotoxin MVIIC-sensitive Ca2+ channel. J Biol Chem 271:13804-13810.

Liu S, Zhou L, Yuan H, Vieira M, Sanz-Clemente A, Badger JD 2nd, Lu W, Traynelis SF, Roche KW (2017) A rare variant identified within the GluN2B C-terminus in a patient with autism affects NMDA receptor surface expression and spine density. J Neurosci 37:4093-4102.

Luo Y, Ma H, Zhou JJ, Li L, Chen SR, Zhang J, Chen L, Pan HL (2018) Focal cerebral ischemia and reperfusion induce brain injury through $\alpha 2 \delta$-1bound NMDA receptors. Stroke 49:2464-2472.

Lussier MP, Sanz-Clemente A, Roche KW (2015) Dynamic regulation of NMethyl-d-aspartate (NMDA) and $\alpha$-Amino-3-hydroxy-5-methyl-4-isoxazolepropionic acid (AMPA) receptors by posttranslational modifications. J Biol Chem 290:28596-28603.

Ma H, Chen SR, Chen H, Zhou JJ, Li DP, Pan HL (2018) $\alpha 2 \delta$-1 couples to NMDA receptors in the hypothalamus to sustain sympathetic vasomotor activity in hypertension. J Physiol 596:4269-4283.

Maneuf YP, McKnight AT (2001) Block by gabapentin of the facilitation of glutamate release from rat trigeminal nucleus following activation of protein kinase C or adenylyl cyclase. Br J Pharmacol 134:237-240.

Mao J, Price DD, Mayer DJ (1994) Thermal hyperalgesia in association with the development of morphine tolerance in rats: roles of excitatory amino acid receptors and protein kinase C. J Neurosci 14:2301-2312. 
Mori H, Yamakura T, Masaki H, Mishina M (1993) Involvement of the carboxyl-terminal region in modulation by TPA of the NMDA receptor channel. Neuroreport 4:519-522.

Mori H, Manabe T, Watanabe M, Satoh Y, Suzuki N, Toki S, Nakamura K, Yagi T, Kushiya E, Takahashi T, Inoue Y, Sakimura K, Mishina M (1998) Role of the carboxy-terminal region of the GluR epsilon2 subunit in synaptic localization of the NMDA receptor channel. Neuron 21:571-580.

Nishi H, Hashimoto K, Panchenko AR (2011) Phosphorylation in proteinprotein binding: effect on stability and function. Structure 19:1807-1815.

Oancea E, Meyer T (1998) Protein kinase C as a molecular machine for decoding calcium and diacylglycerol signals. Cell 95:307-318.

Omkumar RV, Kiely MJ, Rosenstein AJ, Min KT, Kennedy MB (1996) Identification of a phosphorylation site for calcium/calmodulindependent protein kinase II in the NR2B subunit of the N-methyl-D-aspartate receptor. J Biol Chem 271:31670-31678.

Pacchiana R, Abbate M, Armato U, Dal Prà I, Chiarini A (2014) Combining immunofluorescence with in situ proximity ligation assay: a novel imaging approach to monitor protein-protein interactions in relation to subcellular localization. Histochem Cell Biol 142:593-600.

Qian Y, Galli A, Ramamoorthy S, Risso S, DeFelice LJ, Blakely RD (1997) Protein kinase $\mathrm{C}$ activation regulates human serotonin transporters in HEK-293 cells via altered cell surface expression. J Neurosci 17:45-57.

Rebola N, Srikumar BN, Mulle C (2010) Activity-dependent synaptic plasticity of NMDA receptors. J Physiol 588:93-99.

Sacco F, Perfetto L, Castagnoli L, Cesareni G (2012) The human phosphatase interactome: an intricate family portrait. FEBS Lett 586:2732-2739.

Salter MW, Kalia LV (2004) Src kinases: a hub for NMDA receptor regulation. Nat Rev Neurosci 5:317-328.

Söderberg O, Leuchowius KJ, Gullberg M, Jarvius M, Weibrecht I, Larsson LG, Landegren U (2008) Characterizing proteins and their interactions in cells and tissues using the in situ proximity ligation assay. Methods 45:227-232.

Sprengel R, Suchanek B, Amico C, Brusa R, Burnashev N, Rozov A, Hvalby O, Jensen V, Paulsen O, Andersen P, Kim JJ, Thompson RF, Sun W, Webster LC, Grant SG, Eilers J, Konnerth A, Li J, McNamara JO, Seeburg $\mathrm{PH}$ (1998) Importance of the intracellular domain of NR2 subunits for NMDA receptor function in vivo. Cell 92:279-289.

Strack S, Colbran RJ (1998) Autophosphorylation-dependent targeting of calcium/calmodulin-dependent protein kinase II by the NR2B subunit of the N-methyl- D-aspartate receptor. J Biol Chem 273:20689-20692.

Tingley WG, Ehlers MD, Kameyama K, Doherty C, Ptak JB, Riley CT, Huganir RL (1997) Characterization of protein kinase A and protein kinase C phosphorylation of the N-methyl-D-aspartate receptor NR1 subunit using phosphorylation site-specific antibodies. J Biol Chem 272:51575166.
Traynelis SF, Wollmuth LP, McBain CJ, Menniti FS, Vance KM, Ogden KK, Hansen KB, Yuan H, Myers SJ, Dingledine R (2010) Glutamate receptor ion channels: structure, regulation, and function. Pharmacol Rev 62:405496.

Wagner DA, Leonard JP (1996) Effect of protein kinase-C activation on the $\mathrm{Mg}(2+)$-sensitivity of cloned NMDA receptors. Neuropharmacology 35:29-36.

Warnet XL, Bakke Krog H, Sevillano-Quispe OG, Poulsen H, Kjaergaard M (2020) The C-terminal domains of the NMDA receptor: how intrinsically disordered tails affect signalling, plasticity and disease. Eur J Neurosci

Xie JD, Chen SR, Pan HL (2017a) Presynaptic mGluR5 receptor controls glutamatergic input through protein kinase C-NMDA receptors in paclitaxel-induced neuropathic pain. J Biol Chem 292:20644-20654.

Xie JD, Chen SR, Chen H, Pan HL (2017b) Bortezomib induces neuropathic pain through protein kinase C-mediated activation of presynaptic NMDA receptors in the spinal cord. Neuropharmacology 123:477-487.

Yamakura T, Mori H, Shimoji K, Mishina M (1993) Phosphorylation of the carboxyl-terminal domain of the zeta 1 subunit is not responsible for potentiation by TPA of the NMDA receptor channel. Biochem Biophys Res Commun 196:1537-1544.

Yan J, Olsen JV, Park KS, Li W, Bildl W, Schulte U, Aldrich RW, Fakler B, Trimmer JS (2008) Profiling the phospho-status of the BKCa channel alpha subunit in rat brain reveals unexpected patterns and complexity. Mol Cell Proteomics 7:2188-2198.

Young LH, Balin BJ, Weis MT (2005) Gö 6983: a fast acting protein kinase C inhibitor that attenuates myocardial ischemia/reperfusion injury. Cardiovasc Drug Rev 23:255-272.

Zhang J, Guan X, Li Q, Meredith AL, Pan HL, Yan J (2018) Glutamate-activated $\mathrm{BK}$ channel complexes formed with NMDA receptors. Proc Natl Acad Sci U S A 115:E9006-e9014.

Zhao YL, Chen SR, Chen H, Pan HL (2012) Chronic opioid potentiates presynaptic but impairs postsynaptic N-methyl-D-aspartic acid receptor activity in spinal cords: implications for opioid hyperalgesia and tolerance. J Biol Chem 287:25073-25085.

Zheng X, Zhang L, Wang AP, Bennett MV, Zukin RS (1999) Protein kinase $\mathrm{C}$ potentiation of $\mathrm{N}$-methyl-D-aspartate receptor activity is not mediated by phosphorylation of N-methyl-D-aspartate receptor subunits. Proc Natl Acad Sci U S A 96:15262-15267.

Zhou HY, Chen SR, Pan HL (2011) Targeting N-methyl-D-aspartate receptors for treatment of neuropathic pain. Expert Rev Clin Pharmacol 4:379-388.

Zhou JJ, Li DP, Chen SR, Luo Y, Pan HL (2018) The $\alpha 2 \delta$-1-NMDA receptor coupling is essential for corticostriatal long-term potentiation and is involved in learning and memory. J Biol Chem 293:19354-19364. 